Published in final edited form as:

Am Econ Rev. 2012 December ; 102(7): 3377-3405. doi:10.1257/aer.102.7.3377.

\title{
Married with children: A collective labor supply model with detailed time use and intrahousehold expenditure information
}

\author{
Laurens Cherchye, \\ Center for Economic Studies, University of Leuven. E. Sabbelaan 53, B-8500 Kortrijk, Belgium \\ (laurens.cherchye@kuleuven-kortrijk.be) \\ Bram De Rock, and \\ ECARES and ECORE, Université Libre de Bruxelles. Avenue F.D. Roosevelt 50, 1050 Brussels, \\ Belgium (bderock@ulb.ac.be) \\ Frederic Vermeulen* \\ Netspar, CentER, Tilburg University. P.O. Box 90153, NL-5000 LE Tilburg, The Netherlands
}

\begin{abstract}
We propose a collective labor supply model with household production that generalizes a model of Blundell, Chiappori and Meghir (2005). Adults'preferences not only depend on own leisure and individual private consumption of market goods. They also depend on the consumption of domestic goods, which are produced by combining market goods with individuals'time. A new identification result, which uses production shifters, is developed. We apply our model to unique data on Dutch couples with children. Our application uses a novel estimation strategy that builds upon the familiar two-stage allocation representation of the collective model.
\end{abstract}

\section{Keywords}

collective model; labor supply; time use; public goods; household production

Parents care for their children. This impacts on their decisions regarding time use and consumption. How can we take this into account when analyzing household behavior? Recently, Blundell, Chiappori and Meghir (2005; henceforth BCM) presented a collective labor supply model that accounts for caring parents, and that has a number of attractive theoretical and conceptual features. We provide a first empirical application of BCM's theoretical ideas. In doing so, we also present a number of extensions to BCM's original analysis to enhance economic realism and to facilitate empirical implementation. In this introductory section, we motivate BCM's collective model to account for caring parents in the analysis of household behavior, and we articulate the main contributions of the current study.

It is by now well established that the unitary model, which assumes that households behave as single decision makers, is not adequate to describe the observed behavior of house-holds 
consisting of multiple individuals. A popular alternative to the unitary model is the collective model, which was originally suggested by Chiappori $(1988,1992)$ and Apps and Rees (1988). This collective model explicitly recognizes that the household consists of multiple individuals who each have their own rational preferences. These individuals are assumed to take Pareto efficient decisions that result from an intrahousehold bargaining process.

Chiappori $(1988,1992)$ originally proposed a collective labor supply model that starts from the rather standard assumption that individuals divide their time between leisure and market work. Interestingly, this model effectively provides a better fit of household labor supply data than the unitary model. ${ }^{1}$ However, as Becker (1965) already noticed, the underlying assumption is too restrictive: in usual settings, not all non-market work can be considered as pure leisure, since time is also spent on household production. Importantly, Apps and Rees (1996) point out that a model that starts from the simple dichotomization of time into leisure and market work may result in misleading welfare recommendations. ${ }^{2}$

In response to this justified critique, Chiappori (1997) has proposed a collective labor supply model that includes household production. ${ }^{3}$ However, the model is again rather specific. It assumes a setting with a single market good and a single domestically produced good, which are both privately consumed. In addition, the sole inputs for the domestic good are the spouses'time allocated to its production. As such, the model does not allow for public consumption in a direct manner, and it abstracts from market goods that act as inputs in the household production process.

BCM presented an alternative model to account for household production in a collective labor supply setting. ${ }^{4}$ It assumes that the parents'individual preferences depend not only on own private consumption and leisure, but also on the children's welfare. Children's welfare then acts as a public good, which is characterized as a Beckerian (1965) domestic good that is produced by means of expenditures on children (like clothing and toys) and parental time invested in children. The model is fully identified in the sense that parents'individual preferences and the decision process, as summarized by the Pareto weights, can be recovered from observed couples'behavior alone.

From a conceptual point of view, an important motivation for BCM's collective model is that it is particularly well-suited for intrahousehold welfare analysis. For example, as argued by BCM, the model provides a natural framework to analyze issues related to the targeting view. This view takes as a starting point that the effectiveness of a specific benefit or tax also depends on the particular household member that is targeted. This last point is most notably illustrated by the rejection of the income pooling hypothesis on numerous occasions. ${ }^{5}$ In addition, the abovementioned identification result enables a sound analysis of statements

\footnotetext{
${ }_{1}^{1}$ See, for example, the empirical applications of Fortin and Lacroix (1997) and Cherchye and Vermeulen (2008).

${ }^{2}$ Donni (2008) derived the conditions that need to be satisfied for welfare analyses still to be valid in the absence of information about the time allocation between market work and household work.

${ }^{3}$ See Aronsson, Daunfeldt and Wikström (2001), Couprie (2007), and Rapoport, Sofer and Solaz (2011) for empirical applications of the model.

${ }_{5}^{4}$ See Blundell, Chiappori and Meghir (2004) for additional discussion of the model.

${ }^{5}$ See, for example, Thomas (1990), Browning, Bourguignon, Chiappori and Lechene (1994), Lundberg, Pollak and Wales (1997) and Duflo (2003).
} 
such as "mothers care more for children than fathers" or "empowering mothers is more beneficial to children than empowering fathers". 6

The theoretical and conceptual attractiveness of BCM's model begs for an empirical application. However, such an application does not yet exist. A likely explanation is that the model implies severe data requirements. For example, it requires detailed knowledge about how the household's total expenditures are broken down in different expenditure categories (including expenditures on children). Furthermore, the model needs specific information on time use (including parental time invested in children).

The current paper fills this gap in the literature, and brings BCM's theoretical ideas to observational data. More specifically, we provide three contributions. Firstly, we present a first application to a (novel and unique) data set that contains all necessary information to implement BCM's model. The data is drawn from the new LISS (Longitudinal Internet Studies for the Social sciences) panel that is gathered by CentERdata; this panel is representative for the Dutch population. The LISS panel is a regular social survey, to which a questionnaire was added about the intrahousehold allocation of expenditures and detailed

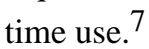

Secondly, we generalize BCM's original model to a setting with more than one domestic good. This generalization seems warranted for the very same reason why a simple dichotomization between market work and leisure may obtain distorted welfare analyses: parents not only allocate their time to market work, parental time and leisure, but also to household activities such as cleaning or gardening. We present a new identification result that is tailored to this generalized model.

Our final contribution is that we propose and apply a novel estimation strategy for our collective model. The strategy is directly based on insights obtained through the well-known two-stage allocation representation of the collective model (see Chiappori, 1988, 1992), and starts from a dual characterization of the model. We will argue that this approach considerably facilitates the derivation of a flexible functional form for the observables. In turn, this greatly benefits the empirical implementation of the theoretical model under study.

As we will discuss, the estimated model obtains intuitive results in terms of the factors that impact on the parental preferences and the Pareto weights. In addition, we show the usefulness of the model for empirical analysis of intrahousehold welfare issues. For example, we will assess the impact of male and female wage changes on the intrahousehold consumption of private goods and leisure, and on the production of public goods (including

\footnotetext{
${ }^{6}$ Dunbar, Lewbel and Pendakur (2010) propose an alternative collective model that focuses on children. This model differs from our model in two important respects. Firstly, Dunbar, Lewbel and Pendakur only focus on the allocation of expenditures and do not consider the allocation of time to market work, leisure and parental time invested in children. Secondly, for identification purposes they need to make the assumption that individual resource shares do not vary with total household expenditures. In addition, they need one of two restrictions on the individual preferences (either involving that preferences for a particular good are similar across individuals or that individual preferences for a particular good are similar across household types).

${ }^{7}$ Our data set is comparable to the one of Bonke and Browning (2009) in the sense that the intrahousehold allocation of all expenditures is known. However, our data set is richer because it also contains detailed information about the time use of the household members. In this respect, another comparable survey is described in Browning and Gøtz (2006). This last survey also includes detailed time use information. However, it focuses on a more limited set of consumption categories.
} 
children's welfare); this complies with the targeting view mentioned above. Next, we will empirically evaluate whether empowering mothers is more beneficial to children than empowering fathers. Finally, we will use the model to estimate indifference scales as introduced by Browning, Chiappori and Lewbel (2008).

The remainder of this paper unfolds as follows. Section I. presents our theoretical model, which generalizes BCM's original model. Section II. contains our empirical application of this model. It presents our data set, proposes our estimation strategy and discusses our empirical results. Section III. concludes.

\section{Theory}

\section{A. The model}

In this section we introduce our collective labor supply model with home production, which extends BCM's original model. Throughout, we will focus on a household with two adults ( $i$ $=1,2$ ). The household further contains children who do not have any bargaining power of their own. The adult members spend their time on leisure (denoted by $\dot{I}$ ), market work (denoted by $\mathrm{m}^{i}$ ) and household work. We make a distinction between two types of household work: parental time invested in children (denoted by $h_{k}^{i}$ ) and other household work like cleaning or gardening (denoted by $h_{p}^{i}$ ). ${ }^{8}$ For each adult member $i$, the time budget constraint thus equals:

$$
l^{i}+m^{i}+h_{k}^{i}+h_{p}^{i}=1
$$

where we normalize the time endowment to one.

One unit of market work by member $i$ is associated with a wage $w^{i}$. The household has a nonlabor income $y$. The income of the household is allocated to a Hicksian composite good with a price that is normalized to one. We assume that the Hicksian composite good is used for the private consumption of the adult members $\left(c^{1}\right.$ and $\left.c^{2}\right)$, expenditures on children $\left(c^{k}\right)$ and expenditures on other public goods $\left(c^{p}\right)$. This results in the following household budget constraint:

$$
c^{1}+c^{2}+c^{k}+c^{p}=y+w^{1} m^{1}+w^{2} m^{2} .
$$

In contrast to what is usually the case, we observe the complete intrahousehold consumption allocation in our data set (see Section II.). In other words, we not only observe how much of the household's resources go towards children and other public goods, but also how the household's private consumption $c^{1}+c^{2}$ is allocated to both adult members.

\footnotetext{
${ }^{8}$ All our results are easily generalized to apply to any number of household work types and public goods. For the sake of simplicity, in what follows we restrict our analysis to two types of household work and public goods. The same setting will be considered in our empirical application in Section II.
} 
The allocation of the household's income (as well as the size of this income) depends on the individual preferences of the adult members and their respective bargaining positions within the household. The preferences of member $i$ are represented by the utility function

$$
u^{i}=u^{i}\left(c^{i}, l^{i}, u^{k}\left(c^{k}, h_{k}^{1}, h_{k}^{2} ; \mathbf{s}^{k}\right), u^{p}\left(c^{p}, h_{p}^{1}, h_{p}^{2} ; \mathbf{s}^{p}\right)\right)
$$

We will assume that the function $u^{i}\left(c^{i}, I^{i}, u^{k}, u^{P}\right)$ is twice continuously differentiable, strictly increasing and strongly concave in all its arguments. The subutility functions $u^{k}$ and $u^{p}$ are assumed to be twice continuously differentiable in all their arguments and to be strictly increasing and strongly concave in the arguments $c^{k}, h_{k}^{1}, h_{k}^{2}$ (respectively $c^{p}, h_{1}^{p}, h_{p}^{2}$ ). In addition, we assume that these subutility functions are linearly homogeneous in the latter arguments, which implies that the household production technologies are characterized by constant returns to scale. ${ }^{9}$ The subutilities represent two domestic goods of which the output is unobserved. More specifically, the domestic good $u^{k}$ stands for the children's utility that acts as a public good in the adult members'preferences. Similarly, the domestic good $u^{p}$ can be interpreted as the joy of a clean and cosy home (though other interpretations are of course possible). We make the standard assumption that the domestic goods are produced in an efficient (i.e. cost minimizing) manner. Contrary to $u^{k}$ and $u^{p}$, individual consumption $c^{1}$ and $c^{2}$ and leisure $l^{1}$ and $P^{2}$ are assumed to be private goods (which do not entail any external effects). ${ }^{10}$

The vectors $\mathbf{s}^{k}$ and $\mathbf{s}^{p}$ in (3) contain production shifters associated with the domestic goods $u^{k}$ and $u^{p}$ (with possibly the same shifters for the two goods). Here, we define a production shifter as a variable that affects individual preferences only through (at least one of) the household production technologies. An example of such a production shifter is the average age of the children in the household; it can be argued that this variable directly influences the household production technology associated with $u^{k}$ (e.g., because younger children require more maternal care than older children, ceteris paribus). In view of our following discussion of identification, we will assume that there is at least one production shifter for one of the two domestic goods (i.e., one of the vectors $\mathbf{s}^{k}$ and $\mathbf{s}^{p}$ has a non-zero dimension). 11

To conclude this introduction of the individual preferences, one remark is in order. It is clear from (3) that we assume that the children's utility $u^{k}$ is produced by means of parental time invested in children and expenditures on children. Still, one can argue that $u^{k}$ also depends on, say, expenditures on housing. This poses the problem that housing affects the adult household members'utility both through $u^{k}$ and $u^{p}$. This problem is very reminiscent of

\footnotetext{
${ }^{9}$ The assumption of constant returns to scale follows Pollak and Wachter (1975) and will prove useful for our identification strategy. ${ }^{10} \mathrm{As}$ is clear from above, the production process focused on is a household technology, which is not necessarily related to individual technologies. See Pollak (2011) for a discussion on the connection between individual and household production technologies.

${ }^{11}$ As indicated above, we assume that the subutility functions are twice continuously differentiable in all their arguments (including the production shifters). For our identification argument (in Online Appendix 1), continuity of the production shifters enables us to consider derivatives with respect to these shifters. We remark that this does not exclude the possibility of discrete production shifters in addition to continuous ones, albeit that such discrete production shifters cannot be used for identification purposes. As a specific example, our empirical application will use the mean age of the children as a continuous production shifter and the number of children as a discrete production shifter.
} 
Gorman's (1978) and Blundell and Robin's (2000) concept of latent separability. ${ }^{12}$ Latent separability generalizes weak separability in the sense that goods are allowed to enter more than one subutility function. However, in the current setting the data forces us to focus on a Hicksian composite commodity with a price that is normalized to one, so that we cannot make use of latent separability. Still, we do see the exploration of this latent separability idea as an interesting avenue for follow-up research; e.g., future waves of the data set used in the present study may generate the required price variation.

The adult members'bargaining positions depend on their wages $w^{1}$ and $w^{2}$, the house-hold's nonlabor income $y$ and a (possibly one-dimensional) vector of distribution factors $\mathbf{z}$. The latter are defined as variables that affect the bargaining position of the adult members without affecting their preferences nor the household budget constraint (after controlling for total income). See Bourguignon, Browning and Chiappori (2009) for a more detailed discussion.

Following Chiappori $(1988,1992)$ and BCM, we assume that the adult members choose Pareto efficient intrahousehold allocations. Therefore, observed allocations are assumed to result from the following optimization programme:

$$
\begin{aligned}
& \max ^{1}, l^{2}, h_{k}^{1}, h_{k}^{2}, h_{p}^{1}, h_{p}^{2}, c^{1}, c^{2}, c^{k}, c^{p}\left(w^{1}, w^{2}, y, \mathbf{z}\right) u^{1}\left(c^{1}, l^{1}, u^{k}\left(c^{k}, h_{k}^{1}, h_{k}^{2} ; \mathbf{s}^{k}\right), u^{p}\left(c^{p}, h_{p}^{1}, h_{p}^{2} ; \mathbf{s}^{p}\right)\right) \\
& +\left(1-\lambda\left(w^{1}, w^{2}, y, \mathbf{z}\right)\right) u^{2}\left(c^{2}, l^{2}, u^{k}\left(c^{k}, h_{k}^{1}, h_{k}^{2} ; \mathbf{s}^{k}\right), u^{p}\left(c^{p}, h_{p}^{1}, h_{p}^{2} ; \mathbf{s}^{p}\right)\right)
\end{aligned}
$$

subject to

$$
\begin{aligned}
c^{1}+c^{2}+c^{k}+c^{p} & =y+w^{1} m^{1}+w^{2} m^{2} \\
l^{i}+m^{i}+h_{k}^{i}+h_{p}^{i} & =1(i=1,2) .
\end{aligned}
$$

The Pareto weight $\lambda\left(w^{1}, w^{2}, y, \mathbf{z}\right)$ represents the relative bargaining power of member 1 as a function of $\left(w^{1}, w^{2}, y, \mathbf{z}\right)$. In what follows, we assume that the Pareto weight is continuously differentiable in all its arguments. ${ }^{13}$ Let the vector $\mathbf{s}$ contain the different production shifters in $\mathbf{s}^{k}$ and $\mathbf{s}^{p}$. Then, the household's optimal choices are observable functions of the adult members'wages $w^{1}$ and $w^{2}$, the household's nonlabor income $y$, the distribution factors $\mathbf{z}$ and the production shifters in $\mathbf{s}(i=1,2)$ :

\footnotetext{
${ }^{12}$ In this respect, see also Pollak and Wachter's (1975) discussion on the issue of joint production in the household (i.e. the same inputs are used for multiple domestic outputs).

13 Just like for the production shifters, this implies that we use continuous distribution factors, which will be helpful for identifying our collective model.
} 


$$
\begin{aligned}
& l^{i}=l^{i}\left(w^{1}, w^{2}, y, \mathbf{z}, \mathbf{s}\right) \\
& c^{i}=c^{i}\left(w^{1}, w^{2}, y, \mathbf{z}, \mathbf{s}\right) \\
& h_{k}^{i}=h_{k}^{i}\left(w^{1}, w^{2}, y, \mathbf{z}, \mathbf{s}\right) \\
& h_{p}^{i}=h_{p}^{i}\left(w^{1}, w^{2}, y, \mathbf{z}, \mathbf{s}\right) \\
& c^{k}=c^{k}\left(w^{1}, w^{2}, y, \mathbf{z}, \mathbf{s}\right) \\
& c^{p}=c^{p}\left(w^{1}, w^{2}, y, \mathbf{z}, \mathbf{s}\right) .
\end{aligned}
$$

At this point, it is worth stressing that the above system of equations is assumed to be completely observed. A natural question now is whether this system of equations allows us to recover the underlying structural model that consists of both adult members'individual preferences and the decision process inside households (as summarized by the Pareto weight). The answer to this question is affirmative as we will demonstrate by means of a new identification result for collective models with several public domestic goods. ${ }^{14}$

\section{B. Identification}

Our identification result is contained in the following proposition, which shows that our model is identified in a generic sense. In particular, generic identification holds under a specific (weak) nonsingularity condition, which pertains to the partial derivatives of the subutility functions $u^{k}$ and $u^{p}$ with respect to one distribution factor $z$ (entry of $\mathbf{z}$ ) and one production shifter $s$ (entry of $\mathbf{s}) .{ }^{15}, 16$

Proposition 1 Let $\left(l^{i}, c^{i}, h_{k}^{i}, h_{p}^{i}, c^{k}, c^{p} ; i=1,2\right)$ be observed functions of $\left(w^{1}, w^{2}, y, \mathbf{z}, \mathbf{s}\right)$ and assume that there exists a distribution factor and a production shifter s such that the matrix $\left[\begin{array}{cc}\frac{\partial u^{k}(\cdot)}{\partial z} & \frac{\partial u^{k}(\cdot)}{\partial s} \\ \frac{\partial u^{p}(.)}{\partial z} & \frac{\partial u^{p}(\cdot)}{\partial s}\end{array}\right]$ is nonsingular in a subset of the domain of $\mathrm{u}^{\mathrm{k}}$ and $\mathrm{u}^{\mathrm{p}}$. Then the individual

preferences are generically identified (or, similarly, collective indirect utilities are generically identified up to a strictly increasing transformation). Moreover, for any

\footnotetext{
${ }^{14}$ See Chiappori and Ekeland (2009) and Donni (2009) for a discussion on the conditions for the identification of collective models with private and public goods where all goods are associated with an own price. The identifiability of a collective labor supply model (without public goods or home production) with several consumption goods that all share the same price is discussed in Chiappori (2011).

${ }^{15}$ We note that the nonsingularity condition in Proposition 1 uses that the domestic goods $\left(u^{k}\right.$ and $u p$ ) can be expressed as a function of the distribution factor $z$, while in the structural model outlined above we have $u^{j}\left(c^{j}, h_{j}^{1}, h_{j}^{2} ; \mathrm{s}^{j}\right)(j=k, p)$. As explained in the proof of Proposition 1, however, we can use that $c^{j}, h_{j}^{1}, h_{j}^{2}$ are functions of $\left(w^{1}, w^{2}, y, \mathbf{z}, \mathbf{s}\right)$. In turn, this obtains $u^{j}\left(w^{1}, w^{2}, y, \mathbf{z}, \mathbf{s}\right)$ (with a slight abuse of notation).

16 While the result in Proposition 1 uses a single distribution factor in combination with a single production factor, identification actually also holds in the case of two production shifters and no distribution factor. The argument in Online Appendix 1 is readily adjusted. Also, the argument is easily extended for the case with more than two domestic goods. In such a situation, identification applies if there are as many production shifters as domestic goods when no distribution factor is available, whereas one needs one less production shifter when (at least one) distribution factor(s) can be used.
} 
cardinalization that represents these individual preferences, the Pareto weight is exactly identified.

Proof. See Online Appendix 1.

Intuitively, the argument underlying this identification result builds on the fact that we can also represent the solution to the optimization programme (4) as stemming from a two-stage allocation process. In the first stage, the household members agree on the level of the domestic goods and an intrahousehold allocation of the residual nonlabor income (which is the nonlabor income minus the expenditures on the inputs that are needed for a given level of the domestic goods). Let us denote member $i$ 's fraction of this residual nonlabor income by $\rho^{i}(i=1,2)$. These functions $\rho^{i}$ define the conditional sharing rule, which generalizes the sharing rule notion that Chiappori (1992) originally introduced for a setting with only private goods. In the second stage, each member maximizes her or his utility by choosing own leisure and own private consumption conditional on the level of both domestic goods and the budget constraint defined in the first stage. The analysis of the two-stage allocation process is also instrumental for our empirical application: we will use it to design the empirical model that we will bring to the data.

Given this two-stage representation, the argument that leads to Proposition 1 (which is formally presented in Online Appendix 1) breaks up in two parts. The first part focuses on the second stage of the allocation process. First of all, this involves the identification of the household production technologies that are represented by $u^{k}$ and $u^{p}$, which exhibit constant returns to scale. Using the assumption of cost minimization in the production of the domestic goods, these subutility functions can be identified in a standard way by means of variation in the wages and variation in the expenditures on the inputs in the respective household production processes.

Next, an important focus in our argument for the second stage is on identifying the sharing rule and the individuals'preferences defined over leisure and consumption (represented by $\left.u^{i}\left(c^{i}, l^{i}, \bar{u}^{k}, \bar{u}^{p}\right) ; i=1,2\right)$ for a given level of the domestic goods $\left(\bar{u}^{k}\right.$ and $\left.\bar{u}^{p}\right)$. Now, the identification can use the variation in the individual wages $w^{1}$ and $w^{2}$ and the residual nonlabor income $\rho^{1}+\rho^{2}$. As proved by Chiappori $(1988,1992)$, the observability of both members'individual labor supply as functions of wages and nonlabor income indeed allows for recovering the sharing rule and the individual preferences. In our case, however, the presence of the domestic goods complicates the identification strategy. The issue is that, in general, the variation in the wages and the nonlabor income also impacts on the level of the domestic goods. Therefore, other variables must come into play to keep these domestic goods constant if we want to make use of Chiappori's identification result. Here, a crucial role is played by the distribution factor $z$ and the production shifter $s$ that are mentioned in Proposition 1 . The nonsingularity condition in the proposition guarantees that our second stage identification problem can be reduced to Chiappori's $(1988,1992)$ original problem with only private goods.

In this respect, one important remark is in order. As demonstrated by Chiappori (1988, 1992), if one only observes the adult members'aggregate consumption $c^{1}+c^{2}$ in addition to 
their individual labor supply, one can identify the sharing rule up to a constant and the individual preferences up to a translation. In our empirical application in Section II., though, we will not have such an unidentified constant, which implies that the sharing rule and the individual preferences are completely identified. The reason is that we observe $c^{1}$ and $c^{2}$ in our data set, which obtains two boundary conditions in the individual integrability problems. Although Chiappori (1992) demonstrated that the unidentified constant is welfare irrelevant in the sense that it does not affect indirect utilities, the above result is useful. For example, it allows us to uniquely characterize the shares that are going to the adult members. Such information is very valuable for policy makers; recall our discussion in the introduction on targeting benefits or taxes to particular household members. More importantly, as we will show below, observing the complete intrahousehold allocation of time and resources considerably facilitates the identification of the first stage of the allocation process.

Summarizing, the first part of the proof of Proposition 1 concentrates on recovering the individuals' preferences defined over leisure and private consumption for a given level of domestic goods. The second part of the proof then focuses on the identification of the tradeoff (in individual preferences) between private consumption and leisure on the one hand, and the different domestic goods on the other. Here, the essential ingredients to the identification argument are the (sufficient) first-order conditions that characterize, for the first stage of the household allocation process, the optimal values for the sharing rule, defined by $\rho^{1}$ and $\rho^{2}$, and the domestic goods $u^{k}$ and $u^{p}$. In particular, a crucial role is played by the BowenLindahl-Samuelson conditions for the optimal provision of public goods inside the household, in combination with our assumption that the subutility functions exhibit constant returns to scale. More specifically, given this assumption of constant returns to scale, there exist linearly homogeneous price indices that we can use to obtain a linear cost (or expenditure) function for each domestic good. Note that these price indices are identified through the identification of the household production technologies.

Plugging these cost functions into the household budget constraint, then, allows us to formally state the first-order conditions mentioned above for the setting at hand. As demonstrated in the proof of Proposition 1, these first-order conditions serve to generically identify the individual preferences over the private goods and the domestic goods. Specifically, the model is identified unless the structural components of our model satisfy two partial differential equations that can be explicitly characterized. Finally, the identification of the individual preferences corresponds to the identification of collective indirect utilities up to a strictly increasing transformation. For any cardinalization of these collective indirect utilities, the Pareto weight is exactly identified.

\section{Empirical application}

\section{A. Data}

We will apply the above collective model to a sample of households drawn from the new LISS panel (Longitudinal Internet Studies for the Social sciences) that is gathered by CentERdata (CentERdata, 2009). The basic panel consists of 5000 households (comprising 8000 individuals) and is representative for the Dutch population. ${ }^{17}$ The first wave of the LISS panel was gathered in 2008. The LISS Core Study is a longitudinal study, which is 
repeated yearly and is designed to follow changes in the life course and living conditions of the panel members. It is comparable in content to standard social surveys. In addition to the LISS Core Study, researchers can collect their own data via online questionnaires presented to the panel members. We made use of this possibility to gather the data necessary to conduct our analysis. This obtains a unique data set that combines detailed assignable expenditures and time use information with a battery of data gathered through a regular social survey.

We added a module on time use and consumption to the LISS panel. This questionnaire was presented to all household members who were at least sixteen years old. The time use data were collected by means of survey questions about the time spent on a set of time use categories during the past seven days. As indicated by Browning and Gørtz (2006), such questions can be informative and have the advantage that they avoid infrequency problems associated with diary-based surveys. Moreover, they are less time-consuming than surveys based on detailed diaries. LISS-respondents had to fill out their time use on thirteen exhaustive categories during the past seven days. ${ }^{18}$ For each category, a number of activities was given as an example along with other useful information. ${ }^{19}$

The consumption module is also based on survey questions on normal individual and household (nondurable) expenditures. The set-up of the questionnaire is partly based on the recommendations by Browning, Crossley and Weber (2003), who conclude that, although survey measures are more noisy than diary measures, they do contain a useful signal on individual consumption. A first set of questions refers to expenditures on twelve categories of goods and services that can be argued to be publicly consumed by the household. Examples of such expenditures are (imputed) rent, expenditures on utilities or formal day care for young children. Although expenditures on food at home are intrinsically private, expenditures on food and drinks used at home and outside home with (other members of) the household appeared in the public expenditures categories. Still, we added a follow-up question where all respondents had to indicate how much of these expenditures they personally consumed. The next set of questions in the consumption module refers to the private expenditures of the respondents, which were gathered in nine categories. Examples of such personal expenditures were food and drinks consumed outside home (but not with other members of the household), clothing, expenditures on leisure activities or personal care. The questionnaire on private expenditures of children less than sixteen years old was completed by one of the adult members.

\footnotetext{
${ }^{17}$ Households without any Internet access are provided with a basic computer (a ,SimPC') that enables them to connect to the Internet. ${ }^{18}$ Since we wanted to maximize the response rate, the questionnaires were online in early September and early December. It is expected that the time use for regular working weeks is fairly well captured. However, the normal yearly time use on summer holidays will be underestimated.

${ }^{19}$ See Online Appendix 2 for detailed lists of the time use categories, public expenditure categories and private expenditure categories that we used in our study. There may be some discussion on the classification of particular expenditure categories as public or private. Therefore, we conducted a sensitivity analysis that involved five alternative classifications, which implied the following differences with respect to the classification used in our main study (reported in the main text): (1) all food expenditures are public; (2) 25\% of the transportation costs are privately consumed by the husband, $25 \%$ by the wife and $50 \%$ by the children; (3) $50 \%$ of the transportation costs are privately consumed by the husband, $25 \%$ by the wife and $25 \%$ by the children; (4) $25 \%$ of the transportation costs are privately consumed by the husband, $25 \%$ by the wife, $25 \%$ by the children and $25 \%$ publicly; (5) $30 \%$ of the transportation costs are privately consumed by the husband, $10 \%$ by the wife, $10 \%$ by the children and $50 \%$ publicly. Our estimation results turn out to be very robust with respect to these alternative classifications; different classifications do not affect our main qualitative conclusions.
} 
The set of households used for this study was subject to the following sample selection rules. We focused attention on couples with children, where both adult members participate in the labor market. After deleting the households with important missing information (mostly, incomplete information on one of the spouses), we obtained a sample of 212 couples with children. This sample is relatively small. Future research could focus on incorporating nonparticipation in the labor market in our theoretical model, which would yield a considerable number of extra observations; see also our discussion in the concluding section.

As mentioned before, the time use and consumption module is complemented with information from the LISS Core Study. More specifically, information on the household composition, the ages of the household members, their wage rates and the individual and household nonlabor incomes are added. Importantly, the wage rates were not derived by dividing an individual's labor income by the number of hours worked according to the time use module, but rather through division of the labor income by the hours worked according to the LISS Core Study. This will help us to avoid division bias in our empirical application (see Browning and Gøtz, 2006, for a similar approach).

To conclude this data subsection, we report some summary statistics on the core variables used in this study. The adult members'private expenditures $\left(c^{1}\right.$ and $\left.c^{2}\right)$ are equal to the sum of all the individual expenditures on the nine categories of goods and services in the private expenditures questionnaire and the own share in the expenditures on food and drinks (which is obtained by the follow-up question on own food consumption in the public expenditures questionnaire). The expenditures on children $\left(c^{k}\right)$ are equal to the sum of the expenditures on child care (obtained through the public expenditures questionnaire) and the sum of all the children's private expenditures (obtained through the private expenditures questionnaire completed either by children aged at least sixteen or by one the adult members for children below that age). The expenditures on the other public good $\left(c^{D}\right)$ equal the sum of the expenditures on the twelve categories in the public expenditures questionnaire minus the expenditures on food and drinks and expenses on child care. The adult members' time spent on market labor $\left(\mathrm{m}^{1}\right.$ and $\mathrm{m}^{2}$ ) is equal to the sum of the time spent on paid work and commuting. Parental time invested in children $\left(h_{k}^{1}\right.$ and $\left.h_{k}^{2}\right)$ includes all time spent on activities with children (such as dressing, playing, visits to the doctor, etc.). Finally, time spent on other public goods $\left(h_{p}^{1}\right.$ and $h_{p}^{2}$ ) equals the sum of all time spent on domestic work (cleaning, gardening, cooking, etc.) and administrative tasks related to the own household.

As is clear from Table 1, wives have, on average, slightly less private expenditures (302 euros per month) than their husbands (311 euros per month). Expenditures on children are, on average, equal to about 479 euros per month. Most of the household's expenditures are spent on other public goods: on average, households spend about 1828 euros per month on these goods. Next, when looking at the adult members'time use, we find that husbands spend substantially more hours on market work than their wives: on average, husbands work about 47.7 hours per week for pay (including commuting), while wives supply about 28.5 hours per week. A different picture emerges when focusing on child care and other home work. Husbands spend on average about 9 hours per week on their children, while they are engaged in other domestic work for about 11.7 hours per week. The figures for women are 
almost double: average time devoted to child care and other home work equals respectively about 15.4 and 20.7 hours per week. If we add both market work and domestic work together, it appears that husbands work a bit more than their wives (68.4 versus 64.6 hours per week). This result does not differ that much from results obtained in earlier studies based on different data (see, e.g., Burda, Hamermesh and Weil, 2008).

\section{B. Parametric specification}

To introduce the parametric specification used for our theoretical model, we shall refer to the model's two-stage allocation representation discussed before. The reason is that it turns out to be impossible to derive a flexible closed form specification for the observables on the basis of a direct utility representation of the adult members' preferences, if we want to preserve the assumption that leisure and individual consumption are not separable from the unobserved outputs of the household production process. Essentially, the two-stage allocation representation permits the use of individual indirect utility functions, which effectively facilitates the derivation of a rather flexible functional reduced form for the observables.

We assume that the second stage's adult members' preferences concerning leisure and own consumption, conditional on the amount of domestic goods produced, can be represented by the following indirect utility functions $(i=1,2)$ :

$$
v^{i}\left(w^{i}, \rho^{i}, \bar{u}^{k}, \bar{u}^{p}\right)=\frac{\ln \left(w^{i}+\rho^{i}\right)-\ln a^{i}\left(w^{i} ; \bar{u}^{k}, \bar{u}^{p}\right)}{\left(w^{i}\right)^{\beta^{i}}},
$$

where $\ln a^{i}\left(w^{i} ; \bar{u}^{k}, \bar{u}^{p}\right)=\left(\alpha_{1}^{i}\left(\mathbf{d}^{i}\right)+\alpha_{2}^{i} \ln \bar{u}^{k}+\alpha_{3}^{i} \ln \bar{u}^{p}\right) \ln w^{i}$ with $\mathbf{d}^{i}$ a vector of individual taste shifters. These indirect utility functions belong to the PIGLOG class. In fact, using that the Hicksian composite commodity has a normalized price equal to one, they exactly coincide with the indirect utility function underlying Deaton and Muellbauer's (1980) Almost Ideal Demand System. Applying Roy's identity to these indirect utility functions results in the following (conditional) Marshallian demand for leisure and own consumption:

$$
\begin{aligned}
& l^{i}=\left[\left(\alpha_{1}^{i}\left(\mathbf{d}^{i}\right)+\alpha_{2}^{i} \ln \bar{u}^{k}+\alpha_{3}^{i} \ln \bar{u}^{p}\right)+\beta^{i} \ln \left(\frac{w^{i}+\rho^{i}}{a^{i}\left(w^{i} ; \bar{u}^{k}, \bar{u}^{p}\right)}\right)\right] \frac{\left(w^{i}+\rho^{i}\right)}{w^{i}} \\
& c^{i}=\left[\left(1-\alpha_{1}^{i}\left(\mathbf{d}^{i}\right)-\alpha_{2}^{i} \ln \bar{u}^{k}-\alpha_{3}^{i} \ln \bar{u}^{p}\right)-\beta^{i} \ln \left(\frac{w^{i}+\rho^{i}}{a^{i}\left(w^{i} ; \bar{u}^{k}, \bar{u}^{p}\right)}\right)\right]\left(w^{i}+\rho^{i}\right)
\end{aligned}
$$

We shall now focus on the first stage allocation of the household's nonlabor income $y$ to $\left(\rho^{1}\right.$, $\left.\rho^{2}, u^{k}, u^{p}\right)$. We first need to specify the household production technologies that transform expenditures on public goods and the spouses'time spent on home production into the domestic goods $u^{k}$ and $u^{p}$. We assume that these technologies are of the constant elasticity of substitution form (see Arrow, Chenery, Minhas and Solow, 1961) $(j=k, p)$ : 


$$
u^{j}\left(c^{j}, h_{1}^{j}, h_{j}^{2} ; \mathbf{s}^{j}\right)=\left(\gamma_{j}^{1}\left(h_{j}^{1}\right)^{\epsilon^{j}\left(\mathbf{s}^{j}\right)}+\gamma_{j}^{2}\left(h_{j}^{2}\right)^{\epsilon^{j}\left(\mathbf{s}^{j}\right)}+\gamma_{j}^{3}\left(c^{j}\right)^{\epsilon^{j}\left(\mathbf{s}^{j}\right)}\right)^{\overline{\epsilon^{j}\left(\mathbf{s}^{j}\right)}}
$$

where $\varepsilon^{j}\left(\mathrm{~s}^{j}\right)$ is assumed to depend on the production shifters in $\mathbf{s}^{j}$.

These technologies exhibit constant returns to scale, which implies that the budget constraint associated with the first stage of the allocation process has a simple form that is linear in $\rho^{1}$, $\left.\rho^{2}, u^{k}, u^{p}\right)$. Given the above specifications of the individual indirect utility functions and the household production technologies, the first-stage maximization programme boils down to:

$$
\begin{aligned}
& \max _{\rho^{1}, \rho^{2}, u^{k}, u^{p}} \lambda\left(w^{1}, w^{2}, y, \mathbf{z}\right)\left(\frac{\ln \left(w^{1}+\rho^{1}\right)-\ln a^{1}\left(w^{1} ; u^{k}, u^{p}\right)}{\left(w^{1}\right)^{\beta^{1}}}\right) \\
& +\left(1-\lambda\left(w^{1}, w^{2}, y, \mathbf{z}\right)\left(\frac{\ln \left(w^{2}+\rho^{2}\right)-\ln a^{2}\left(w^{2} ; u^{k}, u^{p}\right)}{\left.\left(w^{2}\right)^{\beta^{2}}\right)}\right)\right.
\end{aligned}
$$

subject to

$$
\rho^{1}+\rho^{2}+g^{k}\left(w^{1}, w^{2}\right) u^{k}+g^{p}\left(w^{1}, w^{2}\right) u^{p}=y
$$

where $(j=k, p)$ :

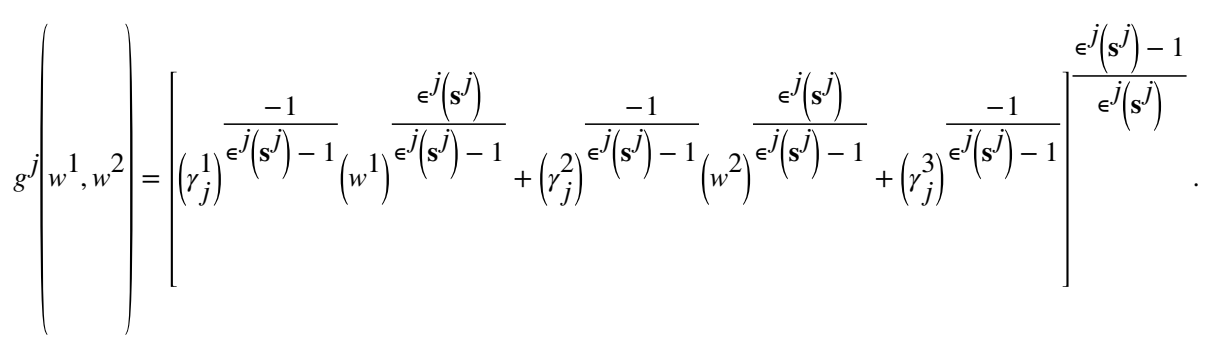

A sufficient condition for a theoretically consistent first stage allocation is that the parameters $\alpha_{2}^{i}$ and $\alpha_{3}^{i}$ in the functions $\ln a^{i}\left(w^{1} ; u^{k}, u^{p}\right)(i=1,2)$ are negative. This condition is imposed on the estimation process by using $\alpha_{l}^{i}=-\exp \left(\tilde{\alpha}_{l}^{i}\right)$, with $\tilde{\alpha}_{l}^{i}$ estimated $(i=1,2 ; l=2$, 3).

Assuming an interior solution, the Lagrangian associated with the above maximization problem results in the following first-order conditions (where $\mu$ is the Lagrange multiplier): 


$$
\begin{aligned}
& \frac{\partial \mathscr{L}}{\partial \rho^{1}}=\frac{\lambda}{\left(w^{1}\right)^{\beta^{1}}} \frac{1}{\left(w^{1}+\rho^{1}\right)}-\mu=0 \\
& \frac{\partial \mathscr{L}}{\partial \rho^{2}}=\frac{1-\lambda}{\left(w^{2}\right)^{\beta^{2}}} \frac{1}{\left(w^{2}+\rho^{2}\right)}-\mu=0 \\
& \frac{\partial \mathscr{L}}{\partial u^{k}}=-\frac{\lambda}{\left(w^{1}\right)^{\beta^{1}}} \frac{\alpha_{2}^{1} \ln w^{1}}{u^{k}}-\frac{(1-\lambda)}{\left(w^{2}\right)^{\beta^{2}}} \frac{\alpha_{2}^{2} \ln w^{2}}{u^{k}}-\mu g^{k}\left(w^{1}, w^{2}\right)=0 \\
& \frac{\partial \mathscr{L}}{\partial u^{p}}=-\frac{\lambda}{\left(w^{1}\right)^{\beta^{1}}} \frac{\alpha_{3}^{1} \ln w^{1}}{u^{p}}-\frac{(1-\lambda)}{\left(w^{2}\right)^{\beta^{2}}} \frac{\alpha_{3}^{2} \ln w^{2}}{u^{p}}-\mu g^{p}\left(w^{1}, w^{2}\right)=0 \\
& \frac{\partial \mathscr{L}}{\partial \mu}=y-\rho^{1}-\rho^{2}-g^{k}\left(w^{1}, w^{2}\right) u^{k}-g^{p}\left(w^{1}, w^{2}\right) u^{p} .
\end{aligned}
$$

Rewriting obtains:

$$
\begin{gathered}
w^{1}+\rho^{1}=\frac{1}{\mu} \frac{\lambda}{\left(w^{1}\right)^{\beta^{1}}} \\
w^{2}+\rho^{2}=\frac{1}{\mu} \frac{1-\lambda}{\left(w^{2}\right)^{\beta^{2}}} \\
g^{k}\left(w^{1}, w^{2}\right) u^{p}=\frac{1}{\mu}\left[-\frac{\lambda}{\left(w^{1}\right)^{\beta^{1}}} \alpha_{3}^{1} \ln w^{1}-\frac{(1-\lambda)}{\left(w^{2}\right)^{\beta^{2}}} \alpha_{3}^{2} \ln w^{2}\right] \\
g^{p}\left(w^{1}, w^{2}\right) u^{p}=\frac{1}{\mu}\left[-\frac{\lambda}{\left(w^{1}\right)^{\beta^{1}}} \alpha_{3}^{1} \ln w^{1}-\frac{(1-\lambda)}{\left(w^{2}\right)^{\beta^{2}}} \alpha_{3}^{2} \ln w^{2}\right] .
\end{gathered}
$$

Summing left- and right-hand sides of these equations, while taking into account that they add up to the household's full budget, results in:

$$
\begin{aligned}
w^{1}+w^{2}+y & =\frac{1}{\mu}\left[\frac{\lambda}{\left(w^{1}\right)^{\beta^{1}}}\left[1-\left(\alpha_{2}^{1}+\alpha_{3}^{1}\right) \ln w^{1}\right]+\frac{(1-\lambda)}{\left(w^{2}\right)^{\beta^{2}}}\left[1-\left(\alpha_{2}^{2}+\alpha_{3}^{2}\right) \ln w^{2}\right]\right. \\
& \equiv \frac{1}{\mu} X\left(w^{1}, w^{2}, \lambda\right),
\end{aligned}
$$

which allows us to derive an expression for $\frac{1}{\mu}$. Substituting this expression in (9) gives the following closed form solutions to the first stage maximization problem: 


$$
\begin{gathered}
\rho^{1}=\frac{w^{1}+w^{2}+y}{X\left(w^{1}, w^{2}, \lambda\right)} \frac{\lambda}{\left(w^{1}\right)^{\beta^{1}}}-w^{1} \\
\rho^{2}=\frac{w^{1}+w^{2}+y}{X\left(w^{1}, w^{2}, \lambda\right)} \frac{(1-\lambda)}{\left(w^{2}\right)^{\beta^{2}}}-w^{2} \\
u^{k}=\frac{w^{1}+w^{2}+y}{X\left(w^{1}, w^{2}, \lambda\right)} \frac{1}{g^{k}\left(w^{1}, w^{2}\right)}\left[-\frac{\lambda}{\left(w^{1}\right)^{\beta^{1}}} \alpha_{2}^{1} \ln w^{1}-\frac{(1-\lambda)}{\left(w^{2}\right)^{\beta^{2}}} \alpha_{2}^{2} \ln w^{2}\right] \\
u^{p}=\frac{w^{1}+w^{2}+y}{X\left(w^{1}, w^{2}, \lambda\right)} \frac{1}{g^{p}\left(w^{1}, w^{2}\right)}\left[-\frac{\lambda}{\left(w^{1}\right)^{\beta^{1}}} \alpha_{3}^{1} \ln w^{1}-\frac{(1-\lambda)}{\left(w^{2}\right)^{\beta^{2}}} \alpha_{3}^{2} \ln w^{2}\right] .
\end{gathered}
$$

Finally, following Browning, Chiappori and Lewbel (2008) we assume that the Pareto weight of the first adult member is of the form:

$$
\lambda\left(w^{1}, w^{2}, y, \mathbf{z}\right)=\frac{\exp \left(\Lambda_{1}+\Lambda_{2} \frac{w^{1}}{w^{2}}+\Lambda_{3 y}+\Lambda_{4}^{\prime} \mathbf{z}\right)}{1+\exp \left(\Lambda_{1}+\Lambda_{2} \frac{w^{1}}{w^{2}}+\Lambda_{3 y}+\Lambda_{4}^{\prime} \mathbf{z}\right)} .
$$

Clearly, this Pareto weight will be between zero and one as the theory requires. By construction, this property extends to the spouse's Pareto weight.

To obtain the individuals'leisure and private consumption as functions of $\left(w^{1} ; w^{2}, y, \mathbf{z}, \mathbf{s}\right)$, we substitute the first stage functions (10) in the second stage functions $(7)(i=1,2)$ :

$$
\begin{aligned}
& l^{1}=\left[A^{i}+\beta^{i}\left(\ln \left(\frac{w^{1}+w^{2}+y}{X\left(w^{1}, w^{2}, \lambda\right)} \frac{\lambda^{i}}{\left(w^{i}\right)^{\beta^{i}}}\right)-A^{i} \ln w^{i}\right)\right] \times \frac{\left(\frac{w^{1}+w^{2}+y}{X\left(w^{1}, w^{2}, \lambda\right)} \frac{\lambda^{i}}{\left(w^{i}\right)^{\beta^{i}}}\right)}{w^{i}} \\
& c^{i}=\left[\left(1-A^{i}\right)-\beta^{i}\left(\ln \left(\frac{w^{1}+w^{2}+y}{X\left(w^{1}, w^{2}, \lambda\right)} \frac{\lambda^{i}}{\left(w^{i}\right) \beta^{i}}\right)-A^{i} \ln w^{i}\right) \times \times\left(\frac{w^{1}+w^{2}+y}{X\left(w^{1}, w^{2}, \lambda\right)} \frac{\lambda^{i}}{\left(w^{i}\right)^{i}}\right),\right.
\end{aligned}
$$

where 


$$
\begin{aligned}
A^{i} \equiv & \alpha_{1}^{i}\left(\mathbf{d}^{i}\right)+\alpha_{2}^{i} \ln \left(\frac{w^{1}+w^{2}+y}{X\left(w^{1}, w^{2}, \lambda\right)} \frac{1}{g^{k}\left(w^{1}, w^{2}\right)}\left[-\frac{\lambda}{\left(w^{1}\right)^{\beta^{1}}} \alpha_{2}^{1} \ln w^{1}-\frac{(1-\lambda)}{\left(w^{2}\right)^{\beta^{2}}} \alpha_{2}^{2} \ln w^{2}\right]\right) \\
& \left.+\alpha_{3}^{i} \ln \left(\frac{w^{1}+w^{2}+y}{X\left(w^{1}, w^{2}, \lambda\right)} \frac{1}{g^{p}\left(w^{1}, w^{2}\right)} \mid-\frac{\lambda}{\left(w^{1}\right)^{\beta^{1}}} \alpha_{3}^{1} \ln w^{1}-\frac{(1-\lambda)}{\left(w^{2}\right)^{\beta^{2}}} \alpha_{3}^{2} \ln w^{2}\right]\right)
\end{aligned}
$$

and

$$
\begin{aligned}
\lambda & =\lambda\left(w^{1}, w^{2}, y, \mathbf{z}\right) \\
\lambda^{1} & =\lambda\left(w^{1}, w^{2}, y, \mathbf{z}\right) \\
\lambda^{2} & =1-\lambda\left(w^{1}, w^{2}, y, \mathbf{z}\right) .
\end{aligned}
$$

To obtain the inputs of the household production process as functions of $\left(w^{1}, w^{2}, y, \mathbf{z}, \mathbf{s}\right)$, we start from the cost functions $g^{k}\left(w^{1} ; w^{2}\right) u^{k}$ and $g^{p}\left(w^{1} ; w^{2}\right) u^{p}$ that are associated with the two domestic goods. Applying Shephard's lemma to these cost functions, and substituting the observable expressions for $u^{k}$ and $u^{p}$ obtained via the first stage allocation (10) in the resulting Hicksian demands, obtains the following specification for the observable inputs of the household production process: 


$$
\begin{aligned}
& \left.h_{k}^{1}=\left(\frac{w^{1}}{\gamma_{k}^{1}}\right)^{\frac{1}{\epsilon^{k}\left(\mathbf{s}^{k}\right)-1}} \frac{w^{1}+w^{2}+y}{X\left(w^{1}, w^{2}, \lambda\right)}\left(g^{k}\left(w^{1}, w^{2}\right)\right)\right)^{\frac{-\epsilon^{k}\left(\mathbf{s}^{k}\right)}{\epsilon^{k}\left(\mathbf{s}^{k}\right)-1}} \\
& \times\left[-\frac{\lambda}{\left(w^{1}\right)^{\beta^{1}}} \alpha_{2}^{1} \ln w^{1}-\frac{(1-\lambda)}{\left(w^{2}\right)^{\beta^{2}}} \alpha_{2}^{2} \ln w^{2}\right] \\
& h_{k}^{2}=\left(\frac{w^{2}}{\gamma_{k}^{2}}\right)^{\frac{1}{\epsilon^{k}\left(\mathbf{s}^{k}\right)-1}} \frac{w^{1}+w^{2}+y}{X\left(w^{1}, w^{2}, \lambda\right)}\left(g^{k}\left(w^{1}, w^{2}\right)\right)^{\frac{-\epsilon^{k}\left(\mathbf{s}^{k}\right)}{\epsilon^{k}\left(\mathbf{s}^{k}\right)-1}} \\
& \times\left[-\frac{\lambda}{\left(w^{1}\right)^{\beta^{1}}} \alpha_{2}^{1} \ln w^{1}-\frac{(1-\lambda)}{\left(w^{2}\right)^{\beta^{2}}} \alpha_{2}^{2} \ln w^{2}\right] \\
& c^{k}=\left(\gamma_{k}^{3}\right)^{\frac{1}{\epsilon^{k}\left(\mathbf{s}^{k}\right)-1}} \frac{w^{1}+w^{2}+y}{X\left(w^{1}, w^{2}, \lambda\right)}\left(g^{k}\left(w^{1}, w^{2}\right)\right)^{\frac{-\epsilon^{k}\left(\mathbf{s}^{k}\right)}{\epsilon^{k}\left(\mathbf{s}^{k}\right)-1}} \\
& \times\left[-\frac{\lambda}{\left(w^{1}\right)^{\beta}} \alpha_{2}^{1} \ln w^{1}-\frac{(1-\lambda)}{\left(w^{2}\right)^{\beta^{2}}} \alpha_{2}^{2} \ln w^{2}\right] \\
& h_{p}^{1}=\left(\frac{w^{1}}{\gamma_{p}^{1}}\right)^{\frac{1}{\epsilon^{p}\left(\mathbf{s}^{p}\right)-1}} \frac{w^{1}+w^{2}+y}{X\left(w^{1}, w^{2}, \lambda\right)}\left(g^{p}\left(w^{1}, w^{2}\right)\right)^{\frac{-\epsilon^{p}\left(\mathbf{s}^{p}\right)}{\epsilon^{p}\left(\mathbf{s}^{p}\right)-1}} \\
& \times\left[-\frac{\lambda}{\left(w^{1}\right)^{\beta^{1}}} \alpha_{3}^{1} \ln w^{1}-\frac{(1-\lambda)}{\left(w^{2}\right)^{\beta^{2}}} \alpha_{3}^{2} \ln w^{2}\right] \\
& h_{p}^{2}=\left(\frac{w^{2}}{\gamma_{p}^{2}}\right)^{\frac{1}{\epsilon^{p}\left(\mathbf{s}^{p}\right)-1}} \frac{w^{1}+w^{2}+y}{X\left(w^{1}, w^{2}, \lambda\right)}\left(g^{p}\left(w^{1}, w^{2}\right)\right)^{\frac{-\epsilon^{p}\left(\mathbf{s}^{p}\right)}{\epsilon^{p}\left(\mathbf{s}^{p}\right)-1}} \\
& \times\left[-\frac{\lambda}{\left(w^{1}\right)^{\beta^{1}}} \alpha_{3}^{1} \ln w^{1}-\frac{(1-\lambda)}{\left(w^{2}\right) \beta^{2}} \alpha_{3}^{2} \ln w^{2}\right]
\end{aligned}
$$

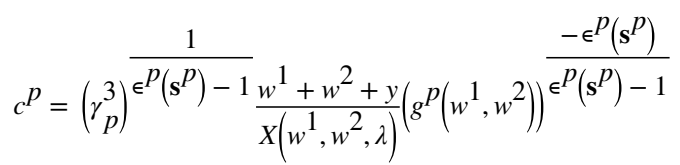

$$
\begin{aligned}
& \times\left[-\frac{\lambda}{\left(w^{1}\right)^{\beta^{1}}} \alpha_{3}^{1} \ln w^{1}-\frac{(1-\lambda)}{\left(w^{2}\right)^{\beta^{2}}} \alpha_{3}^{2} \ln w^{2}\right] .
\end{aligned}
$$

The system brought to the data thus consists of 10 equations. More specifically, we will model $\left(l^{1}, c^{1}, l^{2}, c^{2}, h_{k}^{1}, h_{k}^{2}, c^{k}, h_{p}^{1}, h_{p}^{2}, c^{p}\right)$ as observable functions of $\left(w^{1}, w^{2}, y, \mathbf{z}, \mathbf{s}\right)$. 
We still need to define our taste shifters, production shifters and distribution factors. First, to avoid an overspecified model, we only include age as a taste shifter. Specifically, we use $\alpha_{1}^{i}\left(\mathrm{~d}^{i}\right)=\alpha_{10}^{i}+\alpha_{11}^{i} a g e^{i}(i=1,2)$, where $a g e^{i}$ denotes individual $i$ 's age. Next, we include the number of children (kids) and the mean age of the children (meanagekids) as production shifters for the two domestic goods, by assuming $\epsilon^{j}\left(\mathrm{~s}^{j}\right)=\epsilon_{0}^{j}+\epsilon_{1}^{j} k i d s+\epsilon_{2}^{j}$ meanagekids $(j=k, p)$. Further, we consider two distribution factors: the husband's share in the spouses' individual nonlabor incomes and the age difference between the husband and his spouse.

Finally, to account for unobservable heterogeneity across households, we add additive errors to the system equations. These errors are assumed to be uncorrelated across households but are allowed to correlate across commodities within households. The system is estimated by means of the feasible generalized nonlinear least squares estimator (see Greene, 2008).

\section{Results}

Estimation results-The system of equations forming our structural collective model is highly nonlinear. Therefore, it comes as no surprise that we found several local minima. We selected the lowest local minimum found. Still, we also conducted a robustness check with the parameter values from the other minima found. It is comforting that these additional exercises yielded a broad picture that is qualitatively similar to the one reported here.

Table 2 shows our estimation results; adult member 1 is the husband and adult member 2 is the wife in the household. Despite our relatively small dataset, most parameters turn out to be precisely estimated. ${ }^{20}$ Leisure appears to be a luxury good for both husbands and wives since the estimates of $\beta^{1}$ and $\beta^{2}$ are positive. Leisure and individual consumption turn out to be nonseparable from the outputs of the household production process: both domestic goods have a significant impact on both spouses'leisure and consumption (see the estimates of $\tilde{\alpha}_{2}^{1}, \widetilde{\alpha}_{3}^{1}, \widetilde{\alpha}_{2}^{2}$ and $\widetilde{\alpha}_{3}^{2}$.

Let us then consider the household production technologies. As a first observation, it turns out that one extra time unit spent on children by the mother benefits $u^{k}$ more than one extra time unit spent on children by the father for an equal amount of time spent on children (see the estimates of $\gamma_{k}^{1}$ and $\gamma_{k}^{2}$ ). A similar pattern emerges for the domestic good $u^{p}$, but it is somewhat less pronounced (see $\gamma_{p}^{1}$ and $\gamma_{p}^{2}$ ). Further, both the number of children and the children's mean age significantly affect the production of the domestic good $u^{k}$ (but not of $\left.u^{p}\right)$. Recall that this is a useful finding, as our identification result required at least one (significant) production shifter for at least one domestic good. Our estimates of the household production parameters are most easily interpreted if we calculate the elasticity of substitution, which is defined as $1 /\left(1-\varepsilon^{j}\left(\mathrm{~s}^{j}\right)\right)$ for the given technology. For $u^{k}$, this elasticity

\footnotetext{
${ }^{20}$ The covariance matrix associated with feasible generalized nonlinear least squares makes use of so-called pseudoregressors that involve derivatives of the regression functions. These derivatives were obtained numerically by means of the method of Goldfeldt and Quandt. Still, the approximation error can be substantial given our highly nonlinear system with parameters simultaneously appearing in many terms (see Greene, 2008).
} 
turns out to be equal to about 1 for an average household. It increases with the number of children and decreases with the average age of the children, ceteris paribus. The elasticity of substitution for $u^{p}$ is also fairly high and amounts to 1.18 for the average household. In this case, none of the production shifters that we consider has a statistically significant effect.

Finally, we consider the parameters in the husband's Pareto weight. Both the husband's relative wage and the household's nonlabor income turn out to have a significantly positive impact on this Pareto weight, ceteris paribus. Importantly, because the husband and the wife have different preferences, this implies a strong rejection of the unitary model (which -to recall- models households as if they were single decision making units). Further, the husband's share in the household's nonlabor income has a significantly positive (albeit economically negligible) impact on his Pareto weight. We remark that this implies a rejection of the income pooling hypothesis (consistent with earlier results mentioned in the introduction). Lastly, we observe that also the age difference between the husband and his spouse positively and significantly influences the husband's Pareto weight. Like before, these results are useful in view of our earlier identification argument, which showed that at least one (significant) distribution factor in addition to a (significant) production shifter is sufficient for identification. We may conclude that the setting under study fulfills the conditions for this identification result to apply.

\section{Changing wages: effects on the intrahousehold allocation of resources-Given}

the complexity of our model, the magnitudes of the estimated parameters are not always easy to grasp. Therefore, in what follows we provide some graphical illustrations of the impact of male and female wage changes on the dependent variables in our model. Generally, this impact depends on the complex interaction between individual preferences, intrahousehold bargaining and the household's production technologies. Our following discussion will illustrate the usefulness of the collective model for assessing the effects of wage changes on the intrahousehold consumption of private goods and leisure, and on the production of domestic goods (including children's welfare). As discussed in the introduction, such an analysis can be instrumental for evaluating targeting considerations related to (in casu earned income) benefits or taxes.

Figure 1 focuses on the impact of a change in the husband's wage on the dependent variables. The wage change runs from the first decile to the tenth decile in the male wage distribution, while the other explanatory variables are fixed at their means (including the female's wage). The upper left panel of the figure focuses on the leisure and the private consumption of both husbands and wives. The upper right panel shows the time spent on market labor. The two panels at the bottom show the time and expenditures spent on children and the other domestic good (respectively in the left and the right panel).

As is clear from the figure, the husband's time spent on market work increases when his wage increases. Such a result would also be observed in a standard labor supply model when the substitution effect dominates the income effect. This increase is accompanied by not only a decrease in his leisure but also a decrease in the time spent on children and other household work. At the same time, the husband's own private consumption rises dramatically. In addition, also the household's expenditures on both domestic goods 
increase. This clearly illustrates the trade-off between own consumption on the one hand, and leisure and the utility derived from the domestic goods $\left(u^{k}\right.$ and $\left.u^{p}\right)$ on the other.

A different picture emerges when we look at the impact on the female dependent variables of changing the male wage. It turns out that female leisure decreases as well, while we observe an increase in time spent on home work and market labor (at least when the initial male wage is sufficiently high). Note that this compensates the male's decrease in time spent on children and the other domestic good. Interestingly, also the wife's private consumption increases if the husband's wage increases, but at a slower pace than the husband's private consumption. This is of course not so surprising. Since both spouses supply more market labor hours, the couple's income increases. Part of this income is spent on the domestic goods, while the remainder is allocated to both spouses'private consumption. The latter happens more in favor of the husband, given his increased Pareto weight following his wage rise.

Figure 2 illustrates the impact of a change in the wife's wage on the dependent variables (while, again, keeping the other explanatory variables fixed at their means). The pattern in this figure is somewhat different from the one in Figure 1. While an increase in the male wage decreases the husband's leisure, we now find that the wife's leisure initially increases and then slightly decreases if her wage increases. A reverse picture applies to market labor: if the initial wage is low, female time spent on market labor decreases if her wage increases, while it increases again if her wage reaches above the average wage.

Next, we obtain a similar picture as before for household production. Specifically, time spent on children and the other domestic good decreases if the female wage increases. This decrease is compensated by an increase in the time spent on both domestic goods by the husband. At the same time, male leisure decreases while male time spent on market work initially increases. This last effect clearly demonstrates the negative impact on the husband's Pareto weight of an increase in the wife's wage.

As for consumption, it is clear from Figure 2 that a rise in the wife's wage also implies an increase in both spouses' private consumption, though the pattern differs a bit. In addition, there is an increase in the expenditures on both domestic goods. This again illustrates the trade-off between, on the one hand, private consumption and leisure and, on the other hand, the utility derived from the domestic goods.

To interpret our estimation results further, we also calculated labor supply elasticities defined at the sample median. These elasticities can be found in Table 3. The own wage elasticities are positive, where the husband's elasticity is smaller than the wife's. This falls in line with most of the existing evidence in the labor supply literature. The cross-wage elasticities turn out to be positive. Finally, the husband's nonlabor income elasticity is positive, while the wife's is negative. This positive elasticity for the husband would be difficult to rationalize in a unitary setting, but it is easily understood in a setting with household bargaining and production (hereby also recalling from Table 2 that leisure turns out to be a luxury good for both spouses). 
As a final remark, we indicate that it may be useful to compare these results to the ones for a more basic collective model that does not account for public consumption or household production. It seems interesting to check whether such a basic model specification implies very different estimation results (and corresponding welfare analyses) for households where children are present. We carry out such a comparison in Online Appendix 3. Specifically, we consider a collective model that was originally considered by Chiappori, Fortin and Lacroix (2002). This model is a natural comparison partner because it also incorporates distribution factors to facilitate identification. We estimate the model for the same data and a similar specification of the household member preferences (but without accounting for domestic goods produced in the household).

\section{Empowering mothers or fathers: what is most beneficial to the children (and other public consumption)?-So far, we have focused on the impact of male and} female wage changes on the key variables of the model. A closely related exercise analyzes the extent to which the bargaining power structure, the household production technologies and differences between the husband's and wife's preferences influence the, amounts' of domestic goods $\left(u^{k}\right.$ and $\left.u^{p}\right)$ that are produced within the household. Such an analysis allows us to shed light on a statement like "empowering mothers is more beneficial to children than empowering fathers", where empowering is understood in terms of increasing one's wage. ${ }^{21}$ This complements the existing literature on the (widely observed) phenomenon that changes of the male and female nonlabor incomes have a different impact on the health of children and expenditures on children (see, for example, Thomas, 1990, and Lundberg, Pollak and Wales, 1997).

To tackle the above question, we focus on couples with characteristics equal to their average in the population. To facilitate a ceteris paribus comparison, the average of the spouses' wages is the average across both sexes (which equals about ten euros). Specifically, the full (respectively dotted) lines in Figure 3 correspond to a couple where the wife's (respectively husband's) wage is fixed to this average wage. The left panel then shows the impact of an increase in respectively the husband's and the female's wage on the children's utility $\left(u^{k}\right)$. The right panel shows the impact of wage changes on the production of the other domestic $\operatorname{good}\left(u^{p}\right)$.

The left panel of Figure 3 all but suggests that empowering mothers is more beneficial to children than empowering fathers. To see this, compare two couples. The first couple is situated on the full line (which -to recall- corresponds to an average wage for the female that equals ten euros). Assume for this couple that the husband has an hourly wage of, say, seven euros (which is below the average wage). The second couple is situated on the dotted line (with an average wage for the male that equals ten euros), and we now assume that the female has an hourly wage of seven euros. The figure illustrates that the children's utility is actually higher in the second couple. This provides evidence against the statement that empowering mothers is more beneficial to children than empowering fathers. A similar conclusion holds if we compare a couple on the full line where the husband has a higher than average wage (say, thirteen euros) with a couple on the dotted line where the wife has a

\footnotetext{
${ }^{21}$ This issue is very relevant from a policy perspective (see, for example, Unicef, 2006).
} 
higher than average wage (again thirteen euros): the utility of children is higher for the first couple, although the difference is now much less pronounced than before. Finally, if we consider the right panel of Figure 3, which pertains to the other domestic good $\left(u^{p}\right)$, we observe basically the same pattern as for the children's utility. In fact, the effects are even more pronounced in this case.

Our results for the children's utility may seem surprising at first sight. How can they be explained? Essentially, the overall impact on the children's utility caused by empowering the husband or wife (through a wage increase) is the outcome of a complex interaction between the three structural components of our model: bargaining power, preferences and the household technology. Thus, three mechanisms are at play when comparing the two couples described above. Whether or not empowering mothers or fathers has a beneficial effect on the children's utility is determined by the direction and the relative importance of these three mechanisms. And, as we will explain, these features generally depend on the specific situation at hand.

The first mechanism implies that the wife's bargaining power increases following a female wage raise. This higher bargaining power is reflected by a higher Pareto weight for the wife, which results in household's choices that are more in line with the female's preferences. This effect of a wage increase on the bargaining power is unambiguous. However, the associated impact on the children's welfare crucially depends on the male's and female's preferences. In this respect, it clearly appears from our estimation results that spouses have different preferences. However, if we want to avoid interpersonal utility comparisons, we cannot unambigously interpret the weights attached to children in the respective utility functions. The final mechanism relates to the production technology for children's welfare. Here, we will get substitution from the relatively more expensive input (following a wage increase) to relatively cheaper inputs. For example, from Figures 1 and 2 we know that the female (respectively male) spends more time on the children if the wage of the husband (respectively wife) increases. At the same time, expenditures on children increase when the household gets richer because of a higher wage. The exact substitution pattern does not only depend on the parameter estimates, but also on the level of the wages and the other exogenous variables.

Indifference scales-It is well-known that choice data can only identify the shape and the ranking of indifference curves, but not the utility level attached to these curves. This raises an important problem for equivalence scales: because these equivalence scales aim at defining income levels at which households with different demographic compositions are equally well off, they require interpersonal utility comparisons (see, for example, Lewbel and Pendakur, 2008). Therefore, Browning, Chiappori and Lewbel (2008) proposed socalled indifference scales. Indifference scales measure how much income an individual living alone needs to have in order to be as well off as when living in a couple with some given household income. Since the utility level of the same individual is compared for two different living arrangements, indifference scales are not affected by the particular cardinal representation of the individual preferences and, thus, they do not involve any interpersonal utility comparisons. Naturally, one needs to assume that individual preferences do not change when moving from one living arrangement to another. 
In what follows, we will demonstrate that our model allows for calculating indifference scales. In this respect, the presence of publicly consumed domestic goods (including children's welfare) involves some specific issues. First, because these domestic goods imply production technologies and corresponding (time) inputs from both spouses, we will need to formulate specific assumptions regarding the production technology and the other spouse's (time) inputs when living alone. Next, we can consider alternative situations in terms of the level of the domestic goods when the couple dissolves. We will illustrate the multiple possibilities by reporting results for two types of indifference scales.

Our first type of indifference scales is closest in spirit to the one originally proposed by Browning, Chiappori and Lewbel (2008). In this case, just like for individual preferences, we assume that production technologies are the same in the two living arrangements. Next, we assume that the time inputs of the absent spouse becomes zero when living alone. Finally, we do not impose any restriction on the level of the domestic goods $\left(u^{k}\right.$ and $\left.u^{p}\right)$ in the new situation. All this gives the following indifference scales:

$$
\begin{aligned}
& i s_{t 1}^{1}=\frac{c^{1 *}, c^{k *}, c^{p *}, l^{1 *}, h_{k}^{1 *}, h_{p}^{1 *}\left(\begin{array}{c}
c^{1 *}+c^{k *}+c^{p *}+w^{1}\left(l^{*}+h_{k}^{1 *}+h_{p}^{1 *}\right) \\
s \cdot t \cdot u^{1}\left(c^{1 *}, l^{1 *}, u^{k}\left(c^{k *}, h_{k}^{1 *}, 0\right), u^{p}\left(c^{p *}, h_{p}^{1 *}, 0\right)\right) \\
=u^{1}\left(c^{1}, l^{1}, u^{k}\left(c^{k}, h_{k}^{1}, h_{k}^{2}\right), u^{p}\left(c^{p}, h_{p}, h_{p}^{2}\right)\right)
\end{array}\right)}{w^{1}+w^{2}+y} \\
& i s_{t 1}^{2}=\frac{c^{2 *}, c^{k *}, c^{p *}, l^{2 *}, h_{k}^{2 *}, h_{p}^{2 *}\left(\begin{array}{c}
c^{2 *}+c^{k *}+c^{p *}+w^{2}\left(l^{2 *}+h_{k}^{2 *}+h_{p}^{2 *}\right) \\
\left.s \cdot t \cdot u^{2}\left(c^{2 *}, l^{2 *}, u^{k}\left(c^{k *}, 0, h_{k}^{2 *},\right), u^{p}\left(c^{p *}, 0, h_{p}^{2 *}\right)\right)\right) \\
=u^{2}\left(c^{2}, l^{2}, u^{k}\left(c^{k}, h_{k}^{1}, h_{k}^{2}\right), u^{p}\left(c^{p}, h_{p}^{1}, h_{p}^{2}\right)\right)
\end{array}\right)}{w^{1}+w^{2}+y}
\end{aligned}
$$

The numerator of these indifference scales is equal to the minimum expenditures needed for spouse $i$ living alone to reach the same indifference curve as when (s)he would live in a couple with the initial commodity bundle $\left(c^{i}, c^{k}, c^{p}, l^{i}, h_{k}^{1}, h_{k}^{2}, h_{p}^{1}, h_{p}^{2}\right)$. The denominator is equal to the couple's full income in the initial household situation.

Table 4 gives numerically estimated indifference scales for nine household types defined in terms of full income levels and numbers of children. ${ }^{22} \mathrm{~A}$ first notable observation is that the wife's indifference scales are not defined for any of the cases that we consider. The explanation for this lies in the time constraint, combined with the fact that utility partly depends on domestic goods that need to be produced inside the household. When living alone, the limited time that is available to the wife does not allow her to produce the same level of utility (including domestic goods) as in the initial household situation. Apparently, the economies of scale of living together, as materialized in the publicly consumed domestic goods, are so high that the female spouse will experience a utility loss in any circumstance.

\footnotetext{
${ }^{22}$ We assume that both spouses' wages are in the same quartile of the respective wage distributions. Further, we set the other household characteristics equal to the sample means.
} 
Next, the husband's indifference scales hover around 0.66. This implies that the husband would need about $66 \%$ of the initial household resources to be as well off when living alone. Here, it is worth to recall that we imposed no restriction on the required level of domestic goods when living alone. In fact, it turns out that the indifference scales given in Table 4 imply a negative impact on children: their utility level $u^{k}$ turns out to decrease when moving from a state in which they have both their parents to a state where they live with a single father, even if the father's utility level remains constant (as in the definition of our indifference scales).

Our second type of indifference scales does account for the effects on the children's welfare and other public consumption in case a couple dissolves. In this respect, one can argue that it makes sense to impose that $u^{k}$ and $u^{p}$ remain constant in the new living arrangement. However, here we incur a similar feasibility problem as for the wife's indifference scales discussed above: under the constraint that own utility must be kept at the same level as in the initial (couple) situation, the limited time that is available to a single individual (male or female) does not allow for (additionally) guaranteeing a constant level of domestic goods. To avoid this problem, we calculate indifference scales under the following scenario: the single spouse's time spent on home work stays the same as in the initial situation, and a fraction (fixed at $30 \%$ in our following calculations) of the initial time spent on home work by the now absent partner remains available in the new regime (e.g. because of co-parenting). Then, we keep $u^{k}$ and $u^{p}$ the same as in the initial situation by increasing the expenditures on the domestic goods, to compensate for the decreased time inputs of the absent partner. Again assuming that production technologies are the same in the two living arrangements, we define the following indifference scales:

$$
\begin{aligned}
& i s_{t 2}^{1}=\min _{c^{1 *}, l^{1 *}} \frac{\left(\begin{array}{c}
c^{k}{ }_{k}+c^{p}{ }_{u}{ }^{p}+w^{1}\left(h_{k}^{1}+h_{p}^{1}\right)+w^{2}\left(0.3\left(h_{k}^{2}+h_{p}^{2}\right)\right)+c^{1 *}+w^{1 l 1 *} \\
\text { s.t. } \cdot v^{1}\left(w^{1}, \rho^{1 *}, u^{k}, u^{p}\right)=v^{1}\left(w^{1}, \rho^{1}, u^{k}, u^{p}\right)
\end{array}\right)}{w^{1}+w^{2}+y} \\
& i s_{t 2}^{2}=\min _{c^{2 *}, l^{2 *}} \frac{\left(\begin{array}{c}
c^{k}{ }_{k}+c^{p}{ }^{p} p+w^{2}\left(h_{k}^{2}+h_{p}^{2}\right)+w^{1}\left(0.3\left(h_{k}^{1}+h_{p}^{1}\right)\right)+c^{2 *}+w^{2} l^{2 *} \\
\text { s.t. } \cdot v^{2}\left(w^{2}, \rho^{2 *}, u^{k}, u^{p}\right)=v^{2}\left(w^{2}, \rho^{2}, u^{k}, u^{p}\right)
\end{array}\right)}{w^{1}+w^{2}+y},
\end{aligned}
$$

where $c^{k}{ }_{u}^{k}$ and $c_{u}^{p}{ }^{p}$ represent the expenditures on the domestic goods needed to keep $u^{k}$ and $u^{p}$ at the same level as in the initial situation. Like before, the denominator equals the couple's full income. The numerator now contains two parts: the first four terms give the expenditures that are needed to keep $u^{k}$ and $u^{p}$ constant in the two living arrangements; and the last two terms provide the minimum expenditures of spouse $i$ to reach the same indifference curve as when (s)he would live in a couple with the initial commodity bundle $\left(c^{i}, c^{k}, c^{p}, l^{i}, h_{k}^{l}, h_{k}^{2}, h_{p}^{1}, h_{p}^{2}\right)$, for $u^{k}$ and $u^{p}$ the same as in the original couple. 
Table 5 reports indifference scale estimates for the same nine household types as before. In this case, the time constraint is nowhere problematic (which follows from our specific assumption regarding time spent on the domestic goods by the absent spouse). We find that the husband needs between 80 and $88 \%$ of the initial household resources to be as well off as in a couple. We note that these figures exceed the ones in Table 4. The explanation is that we here impose a constant level of the domestic goods. Next, we observe that the wife needs between 75 and $85 \%$ of the initial household means to reach the same indifference curve as in the initial household situation. Finally, the table reveals that indifference scales increase with the number of children and with the household's full income.

\section{Conclusion}

We proposed a collective labor supply model with household production that generalizes an original model of BCM. Adults'individual preferences not only depend on own leisure and the individual private consumption of market goods, but also on the consumption of domestic goods. This last category of goods is the output of combining goods bought at the market with individuals' time. For example, one of our domestic goods is the children's welfare, which is produced by expenditures on and parental time invested in the children. In our model, we also allow for other domestic goods, which extends the original analysis of BCM. This extension required a new identification strategy. We have shown that a model with two domestic goods is (generically) identified as soon as the empirical analysis includes one distribution factor and one production shifter.

We applied our model to new and unique data with detailed information about the individuals' time use and the intrahousehold allocation of all expenditures. The application uses a novel estimation strategy that builds upon the familiar two-stage allocation representation of the collective model. This estimation strategy allows for a flexible functional specification of observables, which is interesting from an empirical point of view.

Our empirical results for a sample of Dutch couples with children reveal some interesting patterns. Firstly, the spouses' preferences turn out to depend significantly on the consumption of domestically produced goods (including children's welfare). Next, the spouses' Pareto weights vary significantly with the individual wages and the share in the household's nonlabor income. Further, we do not find evidence that empowering mothers is more beneficial to the children than empowering fathers. Instead, when focusing on a couple with average characteristics, our results even suggest an opposite pattern for the sample under study. Finally, we used the model to estimate indifference scales as proposed by Browning, Chiappori and Lewbel (2008).

One issue that we left for future work is that of non-participation in employment; see Donni (2003) and Blundell, Chiappori, Magnac and Meghir (2007) for collective models with nonparticipation in a setting without household production. Such an extension with nonparticipation would not only be useful from a theoretical perspective. It would also greatly benefit practical applications, in that it can imply a lot of additional degrees of freedom (e.g., women with young children who do not supply any market labor). A closely related issue is that children should probably be treated as endogenous in the household 
model (as suggested by Apps and Rees, 2001). We have ignored this in the current study, but do consider it an important topic for further research.

\section{Supplementary Material}

Refer to Web version on PubMed Central for supplementary material.

\section{Acknowledgments}

Cherchye acknowledges financial support from the Research Fund K.U.Leuven through the grant STRT1/08/004. De Rock acknowledges the European Research Council (ERC) for his Starting Grant. Vermeulen acknowledges financial support from the Netherlands Organisation for Scientific Research (NWO) through a VIDI grant. This paper draws on data of the LISS panel of CentERdata. Special thanks go to Marika de Bruijne and Arthur van Soest who helped to construct the questionnaire, and to Guillaume Schollier for research assistance. We thank two anonymous referees for their highly insightful comments, which substantially improved the paper. We are also grateful to Richard Blundell, Olivier Donni, Philipp Kircher, Alice Schoonbroodt and seminar participants in Groningen, Leuven, Louvain-la-Neuve, MIT, Paris and Tilburg for helpful comments.

\section{References}

[1]. Afriat, Sydney. Slutsky and Frobenius. Zeitschrift für Nationalökonomie. 1977; 37(3-4):307-322.

[2]. Apps, Patricia; Ray, Rees. Taxation and the Household. Journal of Public Economics. 1988; 35(3): 355-369.

[3]. Apps, Patricia; Ray, Rees. Labour Supply, Household Production and Intra-Family Welfare Distribution. Journal of Public Economics. 1996; 60(2):199-219.

[4]. Apps, Patricia; Ray, Rees. Household Production, Full Consumption and the Costs of Children. Labour Economics. 2001; 8(6):621-648.

[5]. Aronsson, Thomas; Sven-Olav, Daunfeldt; Magnus, Wikström. Estimating Intra-Household Allocation in a Collective Model with Household Production. Journal of Population Economics. 2001; 14(4):569-584.

[6]. Arrow, Kenneth; Hollis, Chenery; Bagicha, Minhas; Robert, Solow. Capital-Labor Substitution and Economic Efficiency. Review of Economics and Statistics. 1961; 43(3):225-250.

[7]. Becker, Gary. A Theory of the Allocation of Time. Economic Journal. 1965; 75(299):493-517.

[8]. Blundell, Richard; Pierre-André, Chiappori; Thierry, Magnac; Costas, Meghir. Collective Labour Supply: Heterogeneity and Non-Participation. Review of Economic Studies. 2007; 74(2):417445.

[9]. Blundell, Richard; Pierre-André, Chiappori; Costas, Meghir. Collective Labor Supply with Children. 2004. IFS-Working Paper 02/08

[10]. Blundell, Richard; Pierre-André, Chiappori; Costas, Meghir. Collective Labor Supply with Children. Journal of Political Economy. 2005; 113(6):1277-1306.

[11]. Blundell, Richard; Jean-Marc, Robin. Latent Separability: Grouping Goods without Weak Separability. Econometrica. 2000; 68(1):53-84.

[12]. Bonke, Jens; Martin, Browning. Allocation within the Household: Direct Survey Evidence. University of Oxford Department of Economics; 2009. Working Paper 429

[13]. Bourguignon, François; Martin, Browning; Pierre-André, Chiappori. Efficient Intrahousehold Allocations and Distribution Factors: Implications and Identification. Review of Economic Studies. 2009; 76(2):503-528.

[14]. Browning, Martin; François, Bourguignon; Pierre-André, Chiappori; ValØrie, Lechene. Income and Outcomes: A Structural Model of Intrahousehold Allocations. Journal of Political Economy. 1994; 102(6):1067-1096.

[15]. Browning, Martin; Pierre-André, Chiappori; Arthur, Lewbel. Estimating Consumption Economies of Scale, Adult Equivalence Scales and Household Bargaining Power. University of Oxford Department of Economics; 2008. Working Paper 289 
[16]. Browning, Martin; Thomas, Crossley; Guglielmo, Weber. Asking Consumption Questions in General Purpose Surveys. Economic Journal. 2003; 113(491):540-567.

[17]. Browning, Martin; Mette, Gørtz. Spending Time and Money within the Household. University of Oxford Department of Economics; 2006. Working Paper 288

[18]. Burda, Michael; Daniel, Hamermesh; Philippe, Weil. The Distribution of Total Work in the EU and US. In: Tito, Boeri; Michael, Burda; Francis, Kramarz, editors. Working Hours and Job Sharing in the EU and USA. Are Europeans Lazy? Or Americans Crazy?. Oxford University Press; Oxford: 2008.

[19]. CentERdata. Longitudinal Internet Studies for the Social sciences Core Study and Time Use and Consumption Module. 2009. http://www.lissdata.nl

[20]. Cherchye, Laurens; Frederic, Vermeulen. Nonparametric Analysis of Household Labour Supply: Goodness-of-Fit and Power of the Unitary and the Collective Model. Review of Economics and Statistics. 2008; 90(2):267-274.

[21]. Chiappori, Pierre-André. Rational Household Labor Supply. Econometrica. 1988; 56(1):63-89.

[22]. Chiappori, Pierre-André. Collective Labor Supply and Welfare. Journal of Political Economy. 1992; 100(3):437-467.

[23]. Chiappori, Pierre-André. Introducing Household Production in Collective Models of Labor Supply. Journal of Political Economy. 1997; 105(1):191-209.

[24]. Chiappori, Pierre-André. Collective Labor Supply with Many Consumption Goods. Review of Economics of the Household. 2011; 9(2):207-220.

[25]. Chiappori, Pierre-André; Ivar, Ekeland. The Micro Economics of Efficient Group Behavior: Identification. Econometrica. 2009; 77(3):763-799.

[26]. Chiappori, Pierre-André; Bernard, Fortin; Guy, Lacroix. Marriage Market, Divorce Legislation, and Household Labor Supply. Journal of Political Economy. 2002; 110(1):37-72.

[27]. Couprie, Héléne. Time Allocation within the Family: Welfare Implications of Life in a Couple. Economic Journal. 2007; 117(516):287-305.

[28]. Deaton, Angus; John, Muellbauer. An Almost Ideal Demand System. American Economic Review. 1980; 70(3):312-326.

[29]. Donni, Olivier. Collective Household Labor Supply: Non-Participation and Income Taxation. Journal of Public Economics. 2003; 87(5-6):1179-1198.

[30]. Donni, Olivier. Labor Supply, Home Production, and Welfare Comparisons. Journal of Public Economics. 2008; 92(7):1720OE1737.

[31]. Donni, Olivier. A Simple Approach to Investigate Intrahousehold Allocation of Private and Public Consumption Goods. Review of Economics and Statistics. 2009; 91(3):617-628.

[32]. Duflo, Esther. Grandmothers and Granddaughters: Old Age Pension and Intrahousehold Allocation in South Africa. World Bank Economic Review. 2003; 17(1):1-25.

[33]. Dunbar, Geoffrey; Arthur, Lewbel; Krishna, Pendakur. Children's Resources in Collective Households: Identification, Estimation and an Application to Child Poverty in Malawi. Boston College Department of Economics; 2010. Working Paper 758

[34]. Fortin, Bernard; Guy, Lacroix. A Test of the Neo-Classical and Collective Models of Labour Supply. Economic Journal. 1997; 107(443):933-955.

[35]. Gorman, William. More Measures for Fixed Costs. In: Charles, Blackorby; Anthony, Shorrocks, editors. Separability and Aggregation. Collected Works of W.M. Gorman. Volume 1. Clarendon Press; Oxford: 1995. 377-404. 1978

[36]. Greene, William. Econometric Analysis. Pearson Education; Upper Saddle River: 2008.

[37]. Lewbel, Arthur; Krishna, Pendakur. Equivalence Scales. In: Steven, Durlauf; Lawrence, Blume, editors. The New Palgrave Dictionary of Economics. Palgrave Macmillan: 2008.

[38]. Lundberg, Shelly; Robert, Pollak; Terence, Wales. Do Husbands and Wives Pool Resources? Evidence from the UK Child Benefit. Journal of Human Resources. 1997; 32(3):463-480.

[39]. Pollak, Robert. Allocating Time: Individuals' Technologies and Household Technology, Perfect Substitutes and Specialization. 2011. NBERWorking Paper 17529

[40]. Pollak, Robert; Michael, Wachter. The Relevance of the Household Production Function and its Implications for the Allocation of Time. Journal of Political Economy. 1975; 83(2):255-278. 
[41]. Rapoport, Benoît; Catherine, Sofer; Anne, Solaz. Household Production in a Collective Model: Some New Results. Journal of Population Economics. 2011; 24(1):23-45.

[42]. Thomas, Duncan. Intra-Household Resource Allocation: An Inferential Approach. Journal of Human Resources. 1990; 25(4):635-664.

[43]. Unicef. The State of the World's Children 2007. Women and Children. The Double Dividend of Gender Equality. The United Nations Children's Fund; New York: 2006. 

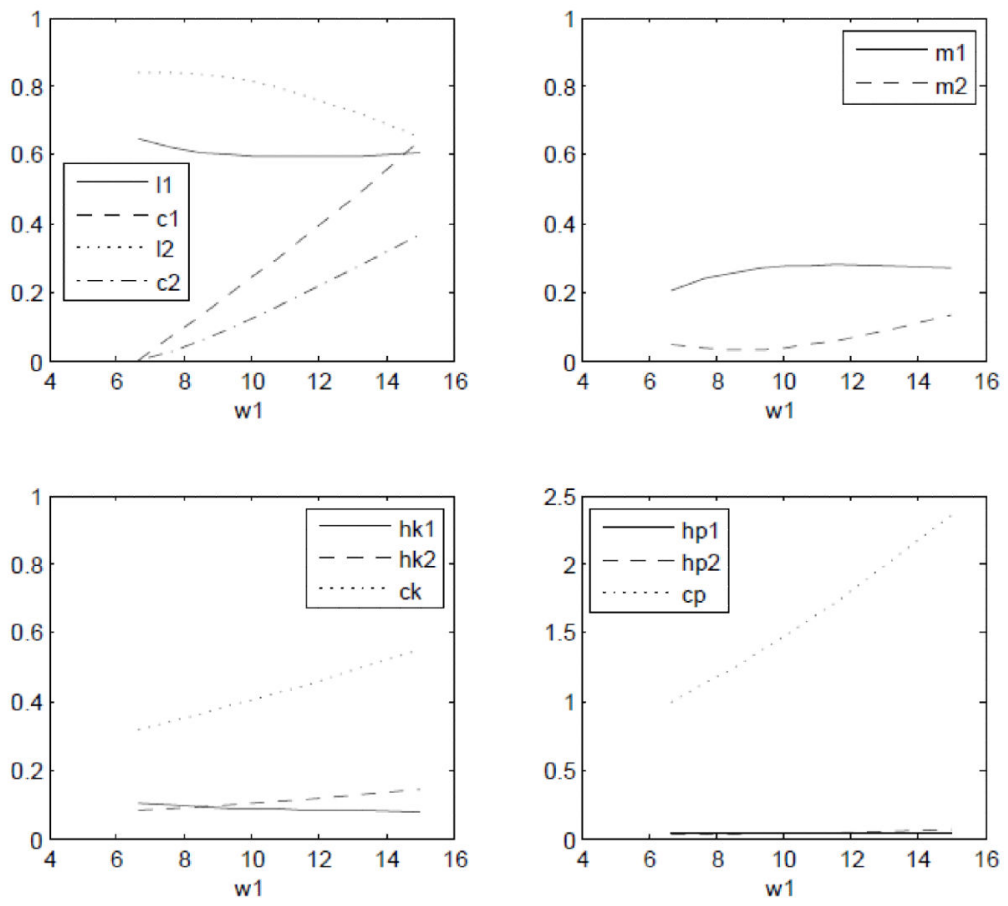

Figure 1.

Impact of change in male wage on dependent variables 

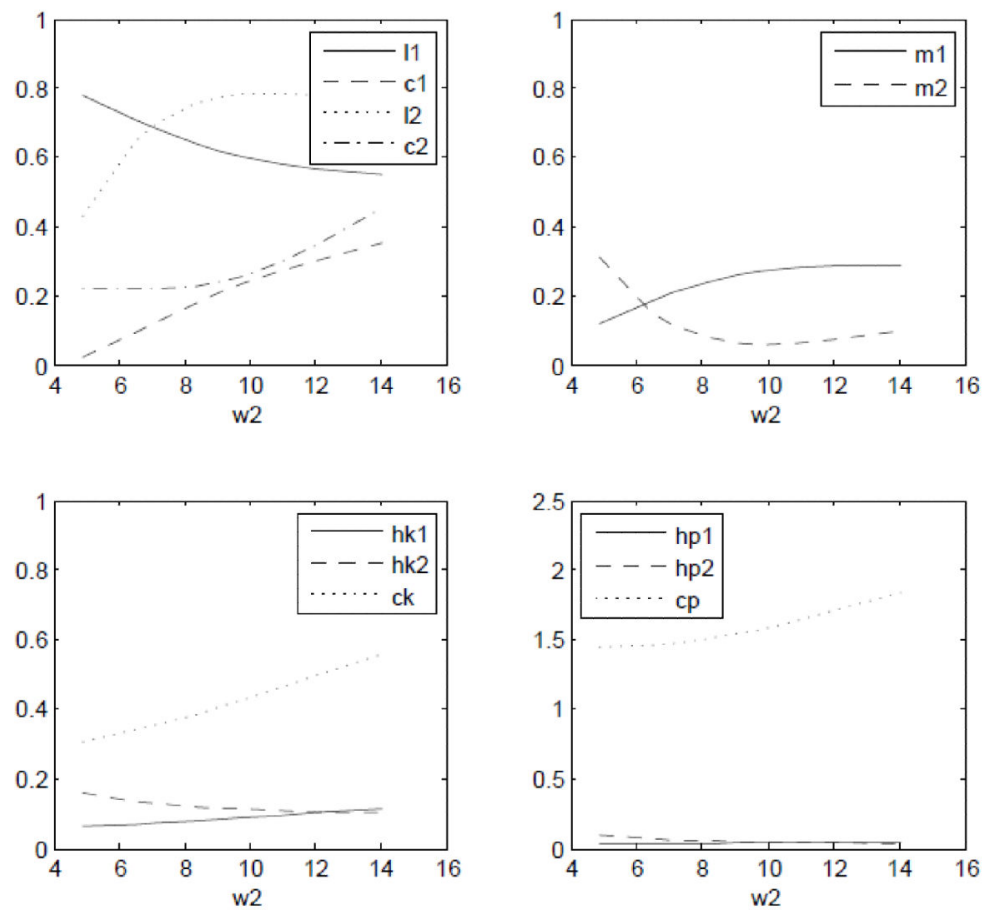

Figure 2.

Impact of change in female wage on dependent variables 

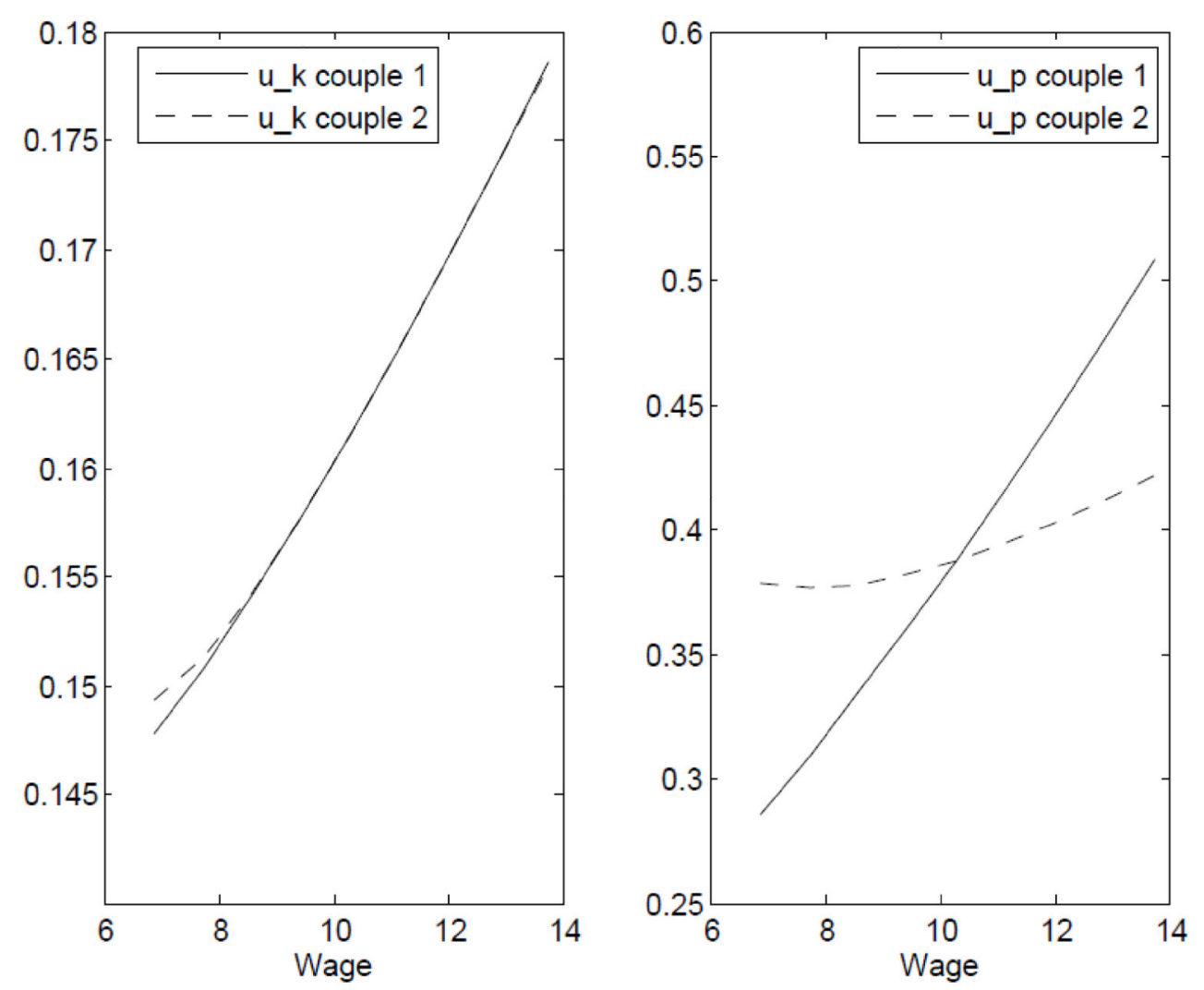

Figure 3.

Impact of change in male and female wages on domestic goods 


\section{Table 1}

Summary statistics LISS couples with children

\begin{tabular}{|c|c|c|c|c|c|c|}
\hline & \multicolumn{2}{|c|}{ Husband } & \multicolumn{2}{|c|}{ Wife } & \multicolumn{2}{|c|}{ Household } \\
\hline & Mean & Std. dev. & Mean & Std. dev. & Mean & Std. dev. \\
\hline \multicolumn{7}{|l|}{ Expenditures } \\
\hline Private expenditures (EUR per month) & 311.08 & 217.10 & 302.64 & 182.41 & & \\
\hline Expenditures on children (EUR per month) & & & & & 479.15 & 493.21 \\
\hline Other public expenditures (EUR per month) & & & & & 1827.77 & 875.32 \\
\hline \multicolumn{7}{|l|}{ Time use } \\
\hline Market lab or (hours per week; incl. commuting) & 47.71 & 11.60 & 28.54 & 11.32 & & \\
\hline Child care (hours per week) & 9.04 & 8.52 & 15.43 & 13.79 & & \\
\hline Other domestic work (hours per week) & 11.66 & 8.22 & 20.65 & 11.75 & & \\
\hline \multicolumn{7}{|l|}{ Socio-economic variables } \\
\hline Age & 42.89 & 7.43 & 40.61 & 7.37 & & \\
\hline Wage rate (EUR per hour) & 10.71 & 3.76 & 9.83 & 5.19 & & \\
\hline Household nonlab or income (EUR per month) & & & & & 130.00 & 330.11 \\
\hline Husband's share in individual nonlab or income & & & & & 0.59 & 0.21 \\
\hline Age difference & & & & & 2.27 & 3.14 \\
\hline Number of children & & & & & 2.02 & 0.75 \\
\hline Mean age of children & & & & & 15.53 & 8.90 \\
\hline
\end{tabular}




\section{Table 2}

Structural estimation results

\begin{tabular}{|c|c|c|}
\hline & Estimate & Std. error \\
\hline \multicolumn{3}{|l|}{ Preference parameters } \\
\hline$\alpha_{10}^{1}$ & $0.826^{*}$ & 0.068 \\
\hline$\alpha_{11}^{1}\left[a g e^{1} / 10\right]$ & $-0.021 *$ & 0.010 \\
\hline$\tilde{\alpha}_{2}^{1}\left[u^{k}\right]$ & $-2.330^{*}$ & 0.356 \\
\hline$\tilde{\alpha}_{3}^{1}\left[u^{p}\right]$ & $-1.842^{*}$ & 0.225 \\
\hline$\beta^{1}$ & $0.209^{*}$ & 0.024 \\
\hline$\alpha_{10}^{2}$ & $0.881^{*}$ & 0.039 \\
\hline$\alpha_{11}^{2}\left[\operatorname{age}^{2} / 10\right]$ & -0.026 & 0.285 \\
\hline$\tilde{\alpha}_{2}^{2}\left[u^{k}\right]$ & $-2.486^{*}$ & 0.289 \\
\hline$\tilde{\alpha}_{3}^{2}\left[u^{p}\right]$ & $-2.876^{*}$ & 0.382 \\
\hline$\beta^{2}$ & $0.159^{*}$ & 0.027 \\
\hline \multicolumn{3}{|c|}{ Household production parameters } \\
\hline$\gamma_{k}^{1}$ & $0.359^{*}$ & 0.011 \\
\hline$\gamma_{k}^{2}$ & $0.417^{*}$ & 0.015 \\
\hline$\gamma_{k}^{3}$ & $0.224^{*}$ & 0.012 \\
\hline$\epsilon_{0}^{k}$ & $0.006^{*}$ & 0.001 \\
\hline$\epsilon_{1}^{k}[k i d s]$ & $-0.017^{*}$ & 0.003 \\
\hline$\epsilon_{2}^{k}[$ meanagekids / 10] & $0.013^{*}$ & 0.003 \\
\hline$\gamma_{p}^{1}$ & $0.196^{*}$ & 0.035 \\
\hline$\gamma_{p}^{2}$ & $0.204 *$ & 0.027 \\
\hline$\gamma_{p}^{3}$ & $0.579^{*}$ & 0.054 \\
\hline$\epsilon_{0}^{p}$ & $0.253^{*}$ & 0.119 \\
\hline$\epsilon_{1}^{p}[k i d s]$ & -0.000 & 0.008 \\
\hline$\epsilon_{2}^{p}[$ meanagekids / 10 $]$ & -0.048 & 0.025 \\
\hline
\end{tabular}

Pareto weight parameters 


\begin{tabular}{lcc}
\hline & Estimate & Std. error \\
\hline$\Lambda_{1}$ & $-1.546^{*}$ & 0.093 \\
$\Lambda_{2}\left[w^{1}=w^{2}\right]$ & $1.395^{*}$ & 0.045 \\
$\Lambda_{3}[y]$ & $1.315^{*}$ & 0.195 \\
$\Lambda_{4}[$ husband's share in nonlabor income] & $0.000^{*}$ & 0.000 \\
$\Lambda_{5}\left[a g e^{1}=10-a g e^{2}=10\right]$ & $0.402^{*}$ & 0.223 \\
\hline
\end{tabular}

Note: Coefficient estimates were obtained by the feasible generalized nonlinear least squares estimator. An asterisk denotes significance at the 5 per cent significance level. The expressions in brackets refer to the objects that are related to the respective parameters. 
Table 3

Labor supply elasticities

\begin{tabular}{ccc}
\hline & Husband & Wife \\
\hline Own wage elasticity & 0.21 & 0.68 \\
Partner's wage elasticity & 0.37 & 1.31 \\
Nonlabor income elasticity & 0.10 & -0.45 \\
\hline
\end{tabular}

Note: Elasticities were calculated numerically for the sample median. 
Table 4

Type 1 indifference scales

\begin{tabular}{ccccccc}
\hline & \multicolumn{2}{c}{ One child } & \multicolumn{2}{c}{ Two children } & \multicolumn{2}{c}{ Three children } \\
& Husband & Wife & Husband & Wife & Husband & Wife \\
\hline First quartile's full income & 0.66 & n.a. & 0.66 & n.a. & 0.66 & n.a. \\
Median full income & 0.65 & n.a. & 0.65 & n.a. & 0.65 & n.a. \\
Third quartile's full income & 0.66 & n.a. & 0.66 & n.a. & 0.66 & n.a. \\
\hline
\end{tabular}

Note: Indifference scales keep the spouses' utility constant across both living arrangements. The scales were numerically obtained. The abbreviation n.a. reveals that the scale cannot be calculated without violating an individual time constraint. 
Table 5

Type 2 indifference scales

\begin{tabular}{cccccccc}
\hline & \multicolumn{2}{c}{ One child } & \multicolumn{2}{c}{ Two children } & \multicolumn{2}{c}{ Three children } \\
& Husband & Wife & Husband & Wife & Husband & Wife \\
\hline First quartile's full income & 0.80 & 0.75 & 0.81 & 0.76 & 0.84 & 0.78 \\
Median full income & 0.80 & 0.80 & 0.82 & 0.81 & 0.85 & 0.83 \\
Third quartile's full income & 0.83 & 0.82 & 0.85 & 0.83 & 0.88 & 0.85 \\
\hline
\end{tabular}

Note: Indifference scales keep the spouses' utility as well as the output of the domestic goods constant across both living arrangements. 